\title{
Transposon-associated TnpB is a programmable RNA-guided DNA endonuclease
}

https://doi.org/10.1038/s41586-021-04058-1

Received: 30 July 2021

Accepted: 27 September 2021

Published online: 7 October 2021

\section{Open access}

Check for updates

\author{
Tautvydas Karvelis ${ }^{1 凶}$, Gytis Druteika', Greta Bigelyte', Karolina Budre', \\ Rimante Zedaveinyte', Arunas Silanskas', Darius Kazlauskas', Česlovas Venclovas' \& \\ Virginijus Siksnys ${ }^{1 凶}$
}

Transposition has a key role in reshaping genomes of all living organisms ${ }^{1}$. Insertion sequences of IS200/IS605 and IS607 families ${ }^{2}$ are among the simplest mobile genetic elements and contain only the genes that are required for their transposition and its regulation. These elements encode tnpA transposase, which is essential for mobilization, and often carry an accessory tnpB gene, which is dispensable for transposition. Although the role of TnpA in transposon mobilization of IS200/IS605 is well documented, the function of TnpB has remained largely unknown. It had been suggested that $\mathrm{TnpB}$ has a role in the regulation of transposition, although no mechanism for this has been established ${ }^{3-5}$. A bioinformatic analysis indicated that TnpB might be a predecessor of the CRISPR-Cas9/Cas12 nucleases ${ }^{6-8}$. However, no biochemical activities have been ascribed to TnpB. Here we show that TnpB of Deinococcus radiodurans ISDra2 is an RNA-directed nuclease that is guided by an RNA, derived from the right-end element of a transposon, to cleave DNA next to the 5'-TTGAT transposon-associated motif. We also show that TnpB could be reprogrammed to cleave DNA target sites in human cells. Together, this study expands our understanding of transposition mechanisms by highlighting the role of TnpB in transposition, experimentally confirms that TnpB is a functional progenitor of CRISPR-Cas nucleases and establishes TnpB as a prototype of a new system for genome editing.
Insertion sequences are widespread mobile genetic elements (MGEs) that only contain genes that are required for transposition and its regulation. Insertion sequences from the IS200/IS605 and IS607 families are among the simplest and most ancient MGEs ${ }^{2}$. Typically, they carry subterminal left end (LE) and right end (RE) palindromic elements at MGE ends and encode either tnpA and t $n p B$ genes in various configurations, or isolated $\operatorname{tnp} A$ or $\operatorname{tn} p B$ genes (ISfinder database) ${ }^{9}$. The well-characterized $D$. radiodurans ISDra 2 of the IS200/IS605 family consists of partially overlapping tnp $A$ and tnp $B$ genes flanked by LE and RE elements ${ }^{10-12}$ (Fig. 1a). The transposon mobilization occurs through a single-strand 'peel and paste' mechanism ${ }^{13}$ (Fig. 1b). ISDra2 TnpA, an extremely small (140 amino acids) Y1 transposase of the HUH family, excises a specific DNA strand near the $5^{\prime}$-TTGAT sequence to form a single-stranded transposon circle that is then integrated $3^{\prime}$ to the TTGAT target in a new location to complete the transposition cycle without duplication of the target site ${ }^{10,12}$. Another well-studied MGE, IS608 from Helicobacter pylori, follows the same mechanism but using a 5'-TTAC tetranucleotide sequence instead of the $5^{\prime}$-TTGAT pentanucleotide targeted by ISDra2 (refs. ${ }^{4,14,15}$ ). In both cases, excision or insertion of a single-stranded transposon circle occurs on the lagging DNA strand at the replication fork, coupling the transposition with the DNA replication cycle of the host ${ }^{16}$.
Although the function of TnpA in transposition is well established, the role of TnpB remains elusive. ISDra2 TnpB (408 amino acids) is not essential for transposition and is thought to regulate excision and insertion of transposons $s^{3-5}$, although a regulatory mechanism has yet to be established. Bioinformatic prediction of the conserved RuvC-like active site in the TnpB sequence led to speculations that TnpB could be an ancestor of Cas 9 and Cas12 nucleases adopted by CRISPR-Cas systems ${ }^{6-8}$. However, neither the role of the RuvC motif in transposition nor the nuclease activity of TnpB have been experimentally demonstrated.

\section{TnpB forms an RNP complex with reRNA}

To establish the biochemical function of TnpB in the $D$. radiodurans ISDra2 element, we aimed to isolate and biochemically characterize the TnpB protein. Initially, we expressed $\operatorname{tnp} B$ fused to the sequence encoding the $10 \times$ His-maltose-binding protein (MBP) tag in Escherichia coli but failed to isolate the intact TnpB protein from cell extracts by $\mathrm{Ni}^{2+}$-affinity chromatography due to low yield (Extended Data Fig. 1a). However, co-expression of $\operatorname{tnp} B$ with a full ISDra2 transposon (with inactivated $\operatorname{tn} p A$ ) resulted in a substantially increased TnpB yield, suggesting that additional transposon elements are required for stable expression of TnpB (Extended Data Fig. 1b,c). Subsequent biochemical 

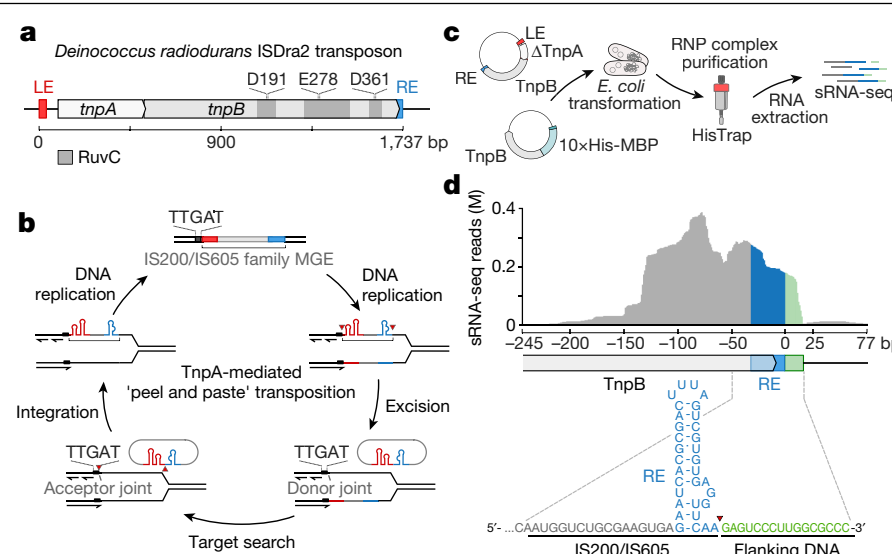

d

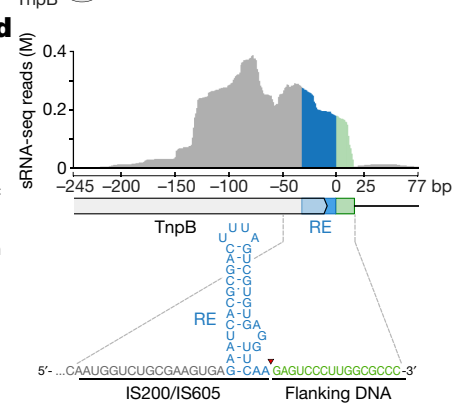

Fig. 1 | ISDra2 MGE of the IS200/IS605 family. a, Schematic representation of the $D$. radiodurans ISDra2 locus. The MGE consists of the tnp $A$ and tnp $B$ genes flanked by left end (LE) and right end (RE) partially palindromic elements (shown in red and blue, respectively). Amino acid residues at the predicted RuvC nuclease active site are indicated above the tnpB gene. b. TnpA-mediated 'peel and paste' transposition mechanism for ISDra2. The TnpA dimer catalyses transposon excision from the lagging strand during DNA replication forming a circular single-stranded DNA intermediate and a donor joint. The excised transposon circle inserts at the acceptor joint into the lagging DNA strand 3 ' to the TTGAT sequence, completing the transposition cycle. Transposon excision/insertion sites are marked by red triangles.c. Experimental workflow of the expression and purification of the TnpB complex from E. colicells and bound RNA extraction. sRNA-seq, small RNA sequencing. d, Alignment of sRNA sequenced reads to the ISDra2 locus. The blue colour shows the RNA sequences derived from the RE element, and the green marks the last $16 \mathrm{nt}$ at the sequenced RNA 3 ' ends, which align with the transposon flanking DNA.

analysis of TnpB samples revealed that RNA co-purified with the TnpB protein (Extended Data Fig. 1d). To characterize TnpB-bound RNAs, we performed small RNA sequencing that revealed the enrichment of non-coding RNAs approximately 150 nucleotides (nt) long derived from ISDra2 transposon RE element that we termed right end element RNAs (reRNAs) (Fig. 1c, d). The reRNA co-purified with TnpB fully matched to the $3^{\prime}$ end of the tnpB gene and RE sequence, except for the last approximately $16 \mathrm{nt}$ at the $3^{\prime}$ end, which were derived from the DNA sequence flanking the IS200/IS605 transposon (Fig. 1d). The enrichment of non-coding RNAs associated with tnp $B$-encoding transposons from the IS200/IS605 family has been previously reported; however, their function remains elusive ${ }^{17,18}$. Here we provide experimental evidence that TnpB forms a ribonucleoprotein (RNP) complex with reRNA derived from the $3^{\prime}$ end of the transposon .

\section{TnpB RNP cleaves DNA in vitro}

Guided by the similarities of TnpB to the CRISPR-Cas12f effector complexes that function as RNA-guided double-stranded DNA (dsDNA) nucleases $^{19}$, we hypothesized that the approximately 16 -nt 3 ' terminal of reRNA, which are derived from the DNA adjacent to the transposon and would be variable per se (Fig. 1d), might function as a guide sequence that directs TnpB to its target and activates DNA cleavage. To test this hypothesis, we adopted the previously developed protospacer adjacent motif (PAM) identification assay for Cas $9 /$ Cas1 12 nucleases $^{19}$. First, we engineered the plasmids encoding TnpB and reRNA, where the $3^{\prime}$-terminal reRNA16-nt sequence was replaced by 16-nt (Fig. 2a) or 20-nt (Extended Data Fig. 2a) sequences that matched the target next to the 7-nt $(7 \mathrm{~N})$ randomized region in the plasmid library. Next, following E. colitransformation and expression, cell lysates containing TnpB RNP complexes were used for plasmid library cleavage. The DNA ends that would result from the plasmid cleavage were repaired by T4 DNA polymerase, subjected to adapter ligation, PCR amplified and sequenced.
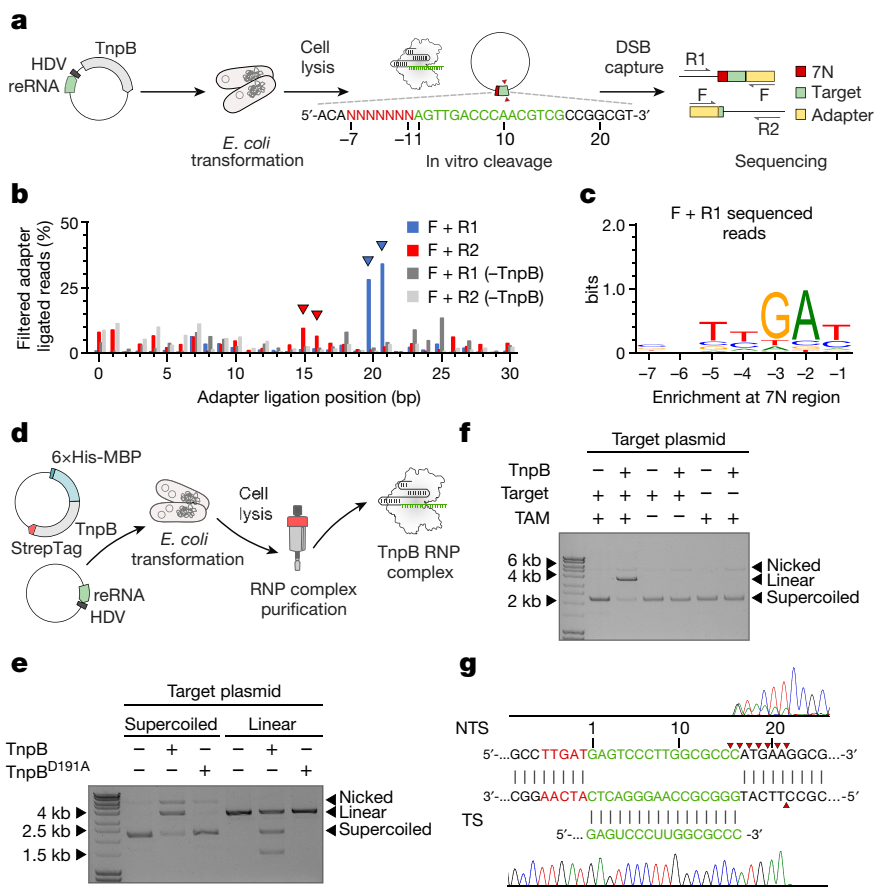

Fig. 2 | TnpB protein is an RNA-guided dsDNA nuclease. a, Experimental workflow for the establishment of dsDNA cleavage requirements by the TnpBreRNA complex. E. coli cells were transformed with a plasmid expressing TnpB and HDV ribozyme-terminated reRNA, containing the 16-nt sequence that matched the target in the plasmid DNA library, flanked by the randomized 7-nt sequence $(7 \mathrm{~N})$. Cell lysate was used for library digestion followed by double-stranded break (DSB) capture. F, forward primer, annealing to the ligated adapter; R1 and R2, reverse primers, annealing to the target plasmid backbone.b, Determination of adapter ligation positions indicate the formation of DSBs in the targeted sequence. '-TnpB' represents the cleavage reactions using lysates obtained from the cells that do not express TnpB. The blue and red triangles indicate the positions of $\mathrm{F}+\mathrm{R} 1$-enriched and $\mathrm{F}+$ R2-enriched adapter ligated reads, respectively. $c$, WebLogo representation of motifs identified in the $7 \mathrm{~N}$ randomized region at 20-21-bp F $+\mathrm{R} 1$-enriched adapter ligated reads. $\mathbf{d}$, Experimental workflow of the expression and purification of the TnpB RNP complex. E. coli cells were transformed with a plasmid expressing TnpB and a separate plasmid expressing HDV ribozyme-terminated reRNA. The reRNA-encoding construct contained the 16-nt guide sequence, which was different from the guide sequence used in the plasmid library cleavage experiment. e, The TnpB RNP complex cleaves supercoiled and linearized target plasmid in vitro. Cleavage is blocked by the D191A mutation at the RuvC-like active site. f, Target plasmid cleavage (TAM+/ Target+, TAM-/Target+ and TAM+/Target-) by the TnpB RNP complex in vitro. TAM and the target complementary to the reRNA3'-end sequence are required for plasmid DNA cleavage. $g$, Sanger sequencing of the TnpB-cleaved plasmid products reveals multiple cleavage positions at the non-targeted strand (NTS) and a single cleavage site at the target strand (TS) (marked with red triangles). For uncropped gel images, see Supplementary Fig.1.

Sequencing of the adapter-ligated fragments revealed enrichment of the products having adapters at the target site $20-21 \mathrm{bp}$ (targeted strand) and $15 \mathrm{bp}$ (non-targeted strand) from the randomized region, indicating cleavage of the plasmid library by the TnpB RNP complex (Fig. 2b, Extended Data Fig. 2b). The positions of the adapter ligation for the targeted strand and non-targeted strand suggested a staggered cleavage pattern generating 5 ' overhangs. Further analysis of DNA fragments revealed enrichment of TTGAT sequences in the randomized $7 \mathrm{~N}$ region $5^{\prime}$ upstream of the target sequence (Fig. 2c, Extended Data Figs. 2c, d, 3). Notably, the TTGAT sequence that licensed cleavage of the plasmid library by TnpB matched the target site sequence that is required for TnpA-mediated ISDra2 transposon excision and inser$\operatorname{tion}^{11}$. Because this sequence was equivalent to the PAM sequence that 

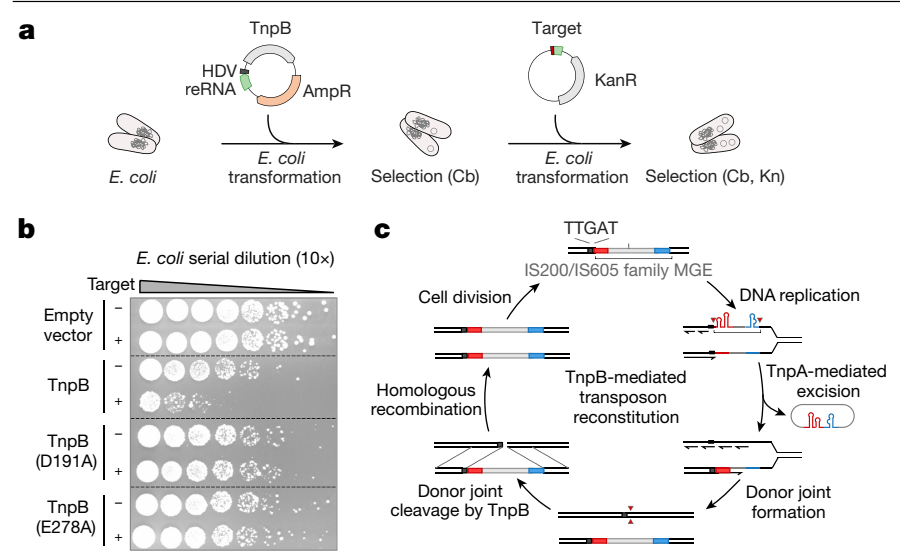

Fig. 3 | TnpB-mediated plasmid interference in vivo. a, Experimental workflow of the plasmid interference assay in $E$. coli. The cleavage of a target plasmid results in loss of kanamycin $(\mathrm{Kn})$ resistance. The reRNA-encoding construct contained the 16-nt guide sequence. AmpR, ampicillin/carbenicillin $(\mathrm{Ap} / \mathrm{Cb})$ resistance gene; KanR, kanamycin resistance gene. $\mathbf{b}$, Plasmid interference assay. E. coli culture samples were serially diluted $(10 \times)$ and the E. coli transformants were grown on the media supplemented with $\mathrm{Cb}$ and $\mathrm{Kn}$ at $25^{\circ} \mathrm{C}$ for $44 \mathrm{~h}$. Interference is compromised for the catalytically dead D191A and E278A TnpB variants. Target ' + ' or '-' indicates the plasmids with or without the target, respectively. For the uncropped plate image, see Supplementary Fig. 1.c, Proposed role of TnpB in transposition. The IS200/IS605 transposon circle is excised from the lagging strand during DNA replication resulting in two DNA copies: one copy that originates from the leading strand and carries an intact transposon, and another copy that originates from the lagging strand and lacks the transposon at the original site due to the strand-specific transposon excision. However, the latter DNA copy still carries the transposon 'footprint' in the form of the donor joint, comprised of the 5'-TTGAT sequence and the $3^{\prime}$-flanking DNA sequence that becomes a target to the TnpB-reRNA complex. In this case, the 5'-TTGAT sequence serves as a TAM that initiates the binding of the reRNA sequence to the matching DNA sequence followed by dsDNA cleavage. TnpB-induced DSB could facilitate homology-directed repair to reinstate the transposon at the donor joint using its intact copy on the sister chromatid, ensuring that both DNA copies have a transposon-coding gene before cell division. Red triangles indicate DNA cleavage sites.

is required for initiation of DNA cleavage by Cas9 or Cas12 nucleases, we termed it transposon-associated motif (TAM).

Next, to validate the requirements for dsDNA cleavage established on the plasmid DNA library, we purified the TnpB-reRNA complex with 1:1 stoichiometry (Fig. 2d, Extended Data Fig. 4) and tested its ability to cleave dsDNA substrates (Fig. 2e, f, Extended Data Fig. 5). First, incubation of the TnpB complex with the plasmid (both supercoiled and linearized), containing the target next to the TAM sequence, converted the supercoiled plasmid into its linear form or yielded linear DNA cleavage products of expected size, respectively (Fig. 2e). Mutation of the conserved D191 residue in the RuvC-like active site compromised cleavage, indicating that the RuvC motif is responsible for cleavage of dsDNA (Fig. 2e). DNA cleavage required both TAM and the target-matching sequence at the 3 ' end of reRNA (Fig. 2f). Last, run-off sequencing of the cleavage products confirmed a staggered cleavage pattern at $15-21 \mathrm{bp}$ from the TAM that resulted in 5 ' overhangs (Fig. 2g). Data for the synthetic oligonucleotide cleavage (Extended Data Fig. 5) were consistent with the plasmid DNA cleavage experiments (Fig. 2e,f). TnpB RNP also cleaved a matching single-stranded DNA in a TAM-independent manner (Extended Data Fig. 6). Together, these results demonstrate that TnpB functions as a TAM-dependent RNA-guided dsDNA nuclease.

\section{TnpB ensures DNA interference in $E$. coli}

To probe whether TnpB is able to cleave its target in the cells, we adopted a plasmid interference assay (Fig. 3a). In brief, E. coli cells expressing a
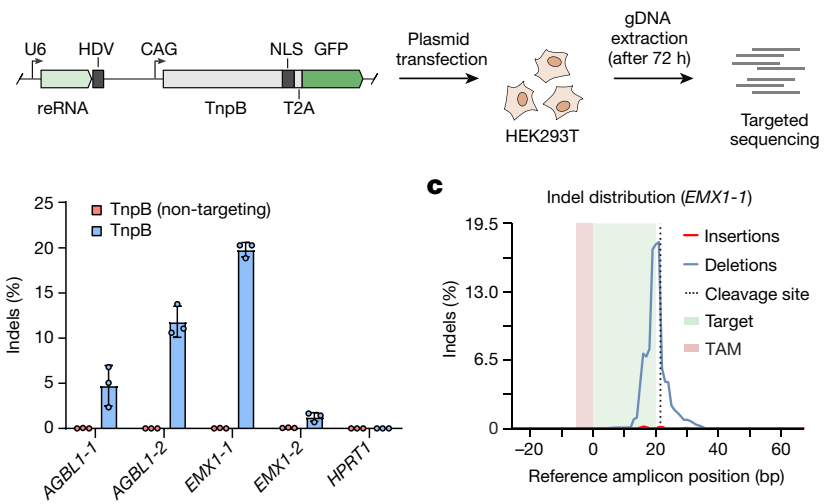

Fig. 4 | TnpB nuclease is a novel genome editor. a, The experimental workflow of the human cell line (HEK293T) genome-editing experiment. NLS, nuclear localization sequence. $\mathbf{b}$, Detection of indel activity in the five tested targets of $20 \mathrm{nt}$ in length in human gDNA (represented as the mean of three biologically independent experiments (shown in dots) \pm standard deviation). The TnpB (non-targeting) expression plasmid used as a negative control encodes the reRNA-containing guide sequence that does not match any target in the human gDNA.c, Indel profile distribution within the target sequence in the EMX1-1 site showing the distribution of deletions (blue line) and insertions (red line) across the cleavage site (dotted line). The profile was obtained by aligning all reads at the $E M X 1-1$ site and counting deletions and insertions at each position.

the TnpB complex were transformed with a plasmid containing the TAM-flanked target and carrying the kanamycin resistance gene that enable growth on kanamycin-supplemented agar plates (Fig. 3a).Serial dilutions of the transformants revealed plasmid interference in the cells containing the native TnpB variant but not TnpB with the mutated RuvC motif (Fig. 3b). Together, these results confirm that TnpB can cleave dsDNA target in vivo. The dsDNA cleavage activity of TnpB and the target site requirements established here allow us to propose the role of TnpB in the transposition of IS200/IS605 MGEs (Fig. 3c). We suggest that TnpB guided by reRNA makes a double-stranded break (DSB) at the 5'-TTGAT flanked donor joint site that is formed in DNA when the transposon circle is excised during replication. A TnpB-induced DSB could then facilitate homology-directed repair to reinstate the transposon at the donor joint using its intact copy on the sister chromatid, ensuring that both DNA copies secured a transposon copy before cell division (Fig. 3c).

\section{TnpB cleaves genomic DNA in human cells}

Finally, after demonstrating RNA-guided dsDNA cleavage both in vitro and in $E$. coli, we tested whether TnpB can be adopted for genome editing of human cells (HEK293T). Plasmids encoding the TnpB protein fused with a nuclear localization sequence and reRNA constructs targeting five 20-nt sites next to the $5^{\prime}$-TTGAT TAM sequence in human genomic DNA (gDNA) were transiently transfected into HEK293T cells (Fig. 4a). After 72 h, gDNA was extracted and analysed by sequencing for the presence of insertions and deletions (indels) at the targeted cleavage sites, indicating DSB repair events and genome editing. At the two tested sites ( $A G B L 1-2$ and $E M X 1-1)$, TnpB introduced mutations at frequencies of $10-20 \%$ (Fig. 4b), similar to the levels observed for CRISPR-Cas9 and Cas12-based editing ${ }^{20-25}$. AGBL1-1 and EMX1-2 sites were moderately (1-5\%) modified, whereas no indels were detected at the HPRT1 site. Further analysis of the obtained indels revealed a domination of deletions at the cleavage site over insertions (Fig. 4c), similar to the mutational profiles observed after Cas12 cleavage ${ }^{23,25}$. Therefore, these results indicate that compact RNA-guided TnpB nucleases can cleave eukaryotic gDNA and may be adopted as tools for genome editing. 


\section{Discussion}

Overall, in this study, we identified the functional activity of the TnpB protein from the ISDra2 system by demonstrating TAM-dependent RNA-guided dsDNA cleavage. This observation expands our understanding of the transposition mechanisms of MGEs in the large IS200/ IS605 family. Although TnpA has been widely studied, revealing the TnpA-mediated 'peel and paste' transposition mechanism, TnpB is not essential for transposition but may have a role in its regulation as it has been suggested for ISDra2 TnpB, although no mechanism for this has been established ${ }^{5}$. The inhibitory effect of TnpB on the excision and integration steps of ISDra 2 transposition reported previously ${ }^{5}$ should be revisited, taking into consideration the RNA-guided TnpB nuclease activity demonstrated in this work.

Here we show that both in vitro (Fig. $2 \mathrm{e}, \mathrm{f}$ ) and in $E$. coli cells (Fig. 3b), TnpB cleaves the donor joint that would be generated after transposon excision and propose that TnpB-mediated DSB triggers homology-directed repair to reinstate the transposon into its original site. This process would be analogous to the group I intron homing promoted by intron encoded endonucleases ${ }^{26}$. We propose that in MGEs containing both tnpA and tnpB, two types of transposition will occur: (1) excision of the transposon and insertion of it at a new site (catalysed by TnpA) (Fig. 1b); and (2) transposon 'homing', a process in which TnpB cuts DNA in a transposon-less allele, triggering recombination that copies the transposon into the same position (Fig. $3 \mathrm{c}$ ). TnpB thus provides a backup mechanism that prevents the possible loss of MGEs if the integration step of the excised transposon is unsuccessful and ensures that both daughter cells will acquire identical DNA copies. In this case, the 'peel and paste' mechanism, which was proposed for TnpA, in the presence of TnpB is transformed into a 'peel, paste and copy' mechanism. The RNA-guided DNA cleavage activity of TnpB could also enable transposon integration into ectopic sites flanked by homologous sequences containing the TAM and matching guide RNA, thus providing an additional mechanism for transposon propagation.

Recently, the evolution of CRISPR-Cas9 nucleases from IscB proteins of the distinct IS200/IS605 transposon family has been reconstructed and RNA-guided DNA cleavage activity of the TnpB protein has been reported; however, the role of TnpB in transposition has not been discussed in detail ${ }^{27}$. The demonstration of the RNA-guided dsDNA cleavage activity of TnpB provides a direct experimental confirmation of an evolutionary scenario for class 2 CRISPR-Cas systems, pinpointing MGEs as predecessors of Cas 9 and Cas12 effectors ${ }^{6-8}$. Sequence comparisons of TnpB and Cas12 family proteins show similar domain organizations, including a conserved RuvC endonuclease-like motif (Extended Data Fig. 7). The closest TnpB neighbours on the evolutionary tree are the miniature Cas12f nucleases ${ }^{8,19,28}$. However, there are important differences between TnpB and the Cas12f nucleases. First, whereas Cas12f nucleases use a guide RNA that originates from the CRISPR array, TnpB uses right transposon element-derived reRNA as a guide. Next, TnpB is a monomer and requires a single reRNA molecule (Extended Data Fig. 3c), whereas Cas12f nucleases are dimers that bind to a single copy of a crRNA (CRISPR RNA)-tracrRNA (trans-activating crRNA) duplex ${ }^{29,30}$. Last, although the TAM sequence required for TnpB cleavage seems to be equivalent to the PAM sequence that licenses Cas12f cleavage, Cas12f proteins show distinct PAM requirements ${ }^{19}$. It would be interesting to see whether the PAM diversity of Cas $12 \mathrm{f}$ nucleases correlate with the distinct TAM sequence requirements of TnpB proteins, reflecting evolutionary relationships between Cas12 nucleases and MGEs of the IS200/IS605/IS607 families. RNA-guided DNA insertion by CRISPR-associated Tn7-like transposons provides another example of the interplay between MGEs and CRISPR-Cas systems ${ }^{31,32}$.

Finally, we show that TnpB also cleaves dsDNA in human cells and expands the genome-editing toolbox by providing a new class of extremely compact non-Cas nucleases with different biochemical requirements for genome-editing applications (Extended Data Table1). The natural diversity of TnpB orthologues, including eukaryotic variants that remain to be characterized ${ }^{33}$, and their miniature size suitable for adeno-associated virus-based delivery open new horizons for human therapeutic applications.

\section{Online content}

Any methods, additional references, Nature Research reporting summaries, source data, extended data, supplementary information, acknowledgements, peer review information; details of author contributions and competing interests; and statements of data and code availability are available at https://doi.org/10.1038/s41586-021-04058-1.

1. Koonin, E. V. Viruses and mobile elements as drivers of evolutionary transitions. Phil. Trans. R. Soc. B 371, 20150442 (2016).

2. Siguier, P., Gourbeyre, E. \& Chandler, M. Bacterial insertion sequences: their genomic impact and diversity. FEMS Microbiol. Rev. 38, 865-891 (2014).

3. Kersulyte, D., Mukhopadhyay, A. K., Shirai, M., Nakazawa, T. \& Berg, D. E. Functional organization and insertion specificity of IS607, a chimeric element of Helicobacter pylori. J. Bacteriol. 182, 5300-5308 (2000).

4. Kersulyte, D. et al. Transposable element ISHp608 of Helicobacter pylori: nonrandom geographic distribution, functional organization, and insertion specificity. J. Bacteriol. 184, 992-1002 (2002).

5. Pasternak, C. et al. ISDra2 transposition in Deinococcus radiodurans is downregulated by TnpB. Mol. Microbiol. 88, 443-455 (2013).

6. Kapitonov, V. V., Makarova, K. S. \& Koonin, E. V. ISC, a novel group of bacterial and archaeal DNA transposons that encode Cas9 homologs. J. Bacteriol. 198, 797-807 (2016).

7. Shmakov, S. et al. Diversity and evolution of class 2 CRISPR-Cas systems. Nat. Rev. Microbiol. 15, 169-182 (2017).

8. Makarova, K. S. et al. Evolutionary classification of CRISPR-Cas systems: a burst of class 2 and derived variants. Nat. Rev. Microbiol. 18, 67-83 (2020)

9. Siguier, P., Perochon, J., Lestrade, L., Mahillon, J. \& Chandler. M. ISfinder: the reference centre for bacterial insertion sequences. Nucleic Acids Res. 34, D32-D36 (2006).

10. Hickman, A. B. et al. DNA recognition and the precleavage state during single-stranded DNA transposition in D. radiodurans. EMBO J. 29, 3840-3852 (2010).

11. Islam, M. S. et al. Characterization and distribution of IS8301 in the radioresistant bacterium Deinococcus radiodurans. Genes Genet. Syst. 78, 319-327 (2003).

12. Pasternak, C. et al. Irradiation-induced Deinococcus radiodurans genome fragmentation triggers transposition of a single resident insertion sequence. PLoS Genet. 6, e1000799 (2010).

13. He, S. et al. The IS200/IS605 family and "peel and paste" single-strand transposition mechanism. Microbiol. Spectr. 3, 3.4.02 (2015).

14. Barabas, O. et al. Mechanism of IS200/IS605 family DNA transposases: activation and transposon-directed target site selection. Cell 132, 208-220 (2008).

15. Guynet, C. et al. In vitro reconstitution of a single-stranded transposition mechanism of IS608. Mol. Cell 29, 302-312 (2008).

16. Hoang, B. T. et al. Single-stranded DNA transposition is coupled to host replication. Cell 142, 398-408 (2010)

17. Gomes-Filho, J. V. et al. Sense overlapping transcripts in IS1341-type transposase genes are functional non-coding RNAs in archaea. RNA Biol. 12, 490-500 (2015).

18. Jäger, D., Förstner, K. U., Sharma, C. M., Santangelo, T. J. \& Reeve, J. N. Primary transcriptome map of the hyperthermophilic archaeon Thermococcus kodakarensis. BMC Genomics 15, 684 (2014).

19. Karvelis, T. et al. PAM recognition by miniature CRISPR-Cas12f nucleases triggers programmable double-stranded DNA target cleavage. Nucleic Acids Res. 48, 5016-5023 (2020).

20. Cong, L. et al. Multiplex genome engineering using CRISPR/Cas systems. Science 339, 819-823 (2013).

21. Jinek, M. et al. RNA-programmed genome editing in human cells. eLife 2, e00471 (2013).

22. Mali, P. et al. RNA-guided human genome engineering via Cas9. Science $\mathbf{3 3 9}, \mathbf{8 2 3 - 8 2 6}$ (2013).

23. Zetsche, B. et al. Cpf1 is a single RNA-guided endonuclease of a class 2 CRISPR-Cas system. Cell 163, 759-771 (2015).

24. Liu, J.-J. et al. CasX enzymes comprise a distinct family of RNA-guided genome editors. Nature 566, 218-223 (2019).

25. Pausch, P. et al. CRISPR-Cas $\Phi$ from huge phages is a hypercompact genome editor. Science 369, 333-337 (2020).

26. Stoddard, B. L. Homing endonucleases from mobile group I introns: discovery to genome engineering. Mob. DNA 5, 7 (2014).

27. Altae-Tran, H. et al. The widespread IS200/605 transposon family encodes diverse programmable RNA-guided endonucleases. Science 374, 57-65 (2021).

28. Harrington, L. B. et al. Programmed DNA destruction by miniature CRISPR-Cas 14 enzymes. Science 362, 839-842 (2018).

29. Takeda, S. N. et al. Structure of the miniature type V-F CRISPR-Cas effector enzyme. Mol. Cell 81, 558-570.e3 (2021). 


\section{Article}

30. Xiao, R., Li, Z., Wang, S., Han, R. \& Chang, L. Structural basis for substrate recognition and cleavage by the dimerization-dependent CRISPR-Cas12f nuclease. Nucleic Acids Res. 49 4120-4128 (2021).

31. Klompe, S. E., Vo, P. L. H., Halpin-Healy, T. S. \& Sternberg, S. H. Transposon-encoded CRISPR-Cas systems direct RNA-guided DNA integration. Nature 571, 219-225 (2019).

32. Strecker, J. et al. RNA-guided DNA insertion with CRISPR-associated transposases. Science 365, 48-53 (2019).

33. Bao, W. \& Jurka, J. Homologues of bacterial TnpB_IS605 are widespread in diverse eukaryotic transposable elements. Mob. DNA 4, 12 (2013).

Publisher's note Springer Nature remains neutral with regard to jurisdictional claims in published maps and institutional affiliations.
Open Access This article is licensed under a Creative Commons Attribution 4.0 International License, which permits use, sharing, adaptation, distribution and reproduction in any medium or format, as long as you give appropriate credit to the original author(s) and the source, provide a link to the Creative Commons license, and indicate if changes were made. The images or other third party material in this article are included in the article's Creative Commons license, unless indicated otherwise in a credit line to the material. If material is not included in the article's Creative Commons license and your intended use is not permitted by statutory regulation or exceeds the permitted use, you will need to obtain permission directly from the copyright holder. To view a copy of this license visit http://creativecommons.org/licenses/by/4.0/.

(c) The Author(s) 2021 


\section{Methods}

\section{Engineering of TnpB expression vectors}

The IS200/IS605 ISDra2 system from D. radiodurans R1 (GenBank AE000513.1) was ordered as a synthetic sequence cloned into the pTwist vector under the T7 promoter (pTWIST-ISDra2; Twist Biosciences). To obtain the ISDra2 variant with a deletion within the tnpA gene (pGD3), the pTWIST-ISDra2 plasmid was pre-cleaved with Ndel (Thermo Fisher Scientific), $5^{\prime}$ overhangs filled-in using T4 DNA polymerase (Thermo Fisher Scientific) and self-circularized with T4 DNA ligase (Thermo Fisher Scientific). For TnpB purification, two pBAD-derived expression vectors were constructed: the tnpB-encoding sequence was fused to $\mathrm{N}$-terminal 10 $\times$ His-TwinStrep-MBP (pTK120-ISDra2-TnpB) or N-terminal $6 \times$ His-MBP and C-terminal StrepTag II (pTK151) protein purification tags and cloned under arabinose-inducible promoters using the NEBuilder HiFi DNA Assembly Kit (New England Biolabs). To obtain the reRNA expression vector (pGB71) for TnpB RNP complex purification, the reRNA-encoding sequence with the T7 promoter at the $5^{\prime}$ end and hepatitis delta virus (HDV) ribozyme with the T7 terminator at the 3 ' end (assembled by PCR from synthetic oligonucleotides) was cloned into the pACYC184 vector between HindIII and Bcll restriction sites (Thermo Fisher Scientific). The self-cleaving HDV ribozyme ensured fixed 16-nt guide RNA length at the 3' end of reRNA. pGB74-78, containing reRNA-encoding and $t n p B$-encoding sequences under 77 and T7lac promoters, respectively, used for TnpB complex expression in $7 \mathrm{~N}$ plasmid library cleavage and plasmid interference assays, were obtained by cloning the reRNA-encoding construct between Bsu15I and EcoRI, and $t n p B$ between Ndel and Xhol (Thermo Fisher Scientific) restriction sites into the pETDuet-1 vector (Novagen). For genome-editing experiments in human HEK293T cells, reRNA (targeting 20-bp sites in human gDNA) and TnpB (fused at the $3^{\prime}$ end with SV40 nuclear localization sequence (NLS)-T2A-GFP) encoding constructs were cloned into the pX458-derived plasmid (a gift from F. Zhang, Addgene plasmid \#48138) under U6 and CAG promoters, respectively (pRZ122-127), using the NEBuilder HiFi DNA Assembly Kit (New England Biolabs). The Phusion Site-Directed Mutagenesis Kit (Thermo Fisher Scientific) was used to obtain plasmid variants with a mutated RuvC active site. The description of the TnpB expression plasmids and links to the sequences are provided in Supplementary Table 1.

\section{Expression and purification of the TnpB RNP complex}

For the initial TnpB protein expression and purification, E. coli BL21-AI cells were transformed with pTK120-ISDra2-TnpB or pTK120-ISDra2-TnpB with pGD3 (plasmid encoding ISDra2 transposon with a deletion within the tnpA gene) and grown in LB medium, supplemented with ampicillin $(100 \mu \mathrm{g} / \mathrm{ml})$ or ampicillin $(100 \mu \mathrm{g} / \mathrm{ml})$ and chloramphenicol $(50 \mu \mathrm{g} / \mathrm{ml})$, respectively, at $37^{\circ} \mathrm{C}$. After culturing to an $\mathrm{OD}_{600}$ of $0.6-0.8$, protein expression was induced with $0.2 \%$ arabinose and the cells were grown for an additional $16 \mathrm{~h}$ at $16^{\circ} \mathrm{C}$. Next, the cells were pelleted by centrifugation, resuspended in $20 \mathrm{mM}$ Tris- $\mathrm{HCl}$ (pH 8.0 at $25^{\circ} \mathrm{C}$ ), $250 \mathrm{mM} \mathrm{NaCl}, 5 \mathrm{mM}$ 2-mercaptoethanol, $25 \mathrm{mM}$ imidazole, $2 \mathrm{mM}$ PMSF and 5\% (v/v) glycerol containing buffer and disrupted by sonication. After removing cell debris by centrifugation, the supernatant was loaded onto the $\mathrm{Ni}^{2+}$-charged HiTrap chelating HP column (GE Healthcare) and proteins were eluted with a linear gradient of increasing imidazole concentration from $25 \mathrm{mM}$ to $500 \mathrm{mM}$ in $20 \mathrm{mM}$ Tris- $\mathrm{HCl}\left(\mathrm{pH} 8.0\right.$ at $\left.25^{\circ} \mathrm{C}\right), 500 \mathrm{mM} \mathrm{NaCl}, 5 \mathrm{mM} 2$-mercaptoethanol and $5 \%(\mathrm{v} / \mathrm{v})$ glycerol buffer. The fractions containing $\mathrm{TnpB}$ were pooled, dialysed against $20 \mathrm{mM}$ Tris- $\mathrm{HCl}\left(\mathrm{pH} 8.0\right.$ at $\left.25^{\circ} \mathrm{C}\right), 250 \mathrm{mM} \mathrm{NaCl}, 2 \mathrm{mM}$ DTT and $50 \%(\mathrm{v} / \mathrm{v})$ glycerol-containing buffer and stored at $-20^{\circ} \mathrm{C}$. The obtained purified TnpB samples were used for nucleic acid extraction and analysis.

For increased expression and yield of the TnpB RNP complex, E. coli BL21-AI cells were transformed with reRNA (pGB71) and TnpB (pTK151) or $\mathrm{TnpB}^{\mathrm{D} 191 \mathrm{~A}}$ ( $\mathrm{pTK} 152$ ) expression vectors and grown in LB medium, supplemented with ampicillin $(100 \mu \mathrm{g} / \mathrm{ml})$ and chloramphenicol $(50 \mu \mathrm{g} / \mathrm{ml})$ at $37^{\circ} \mathrm{C}$. After culturing to an $\mathrm{OD}_{600}$ of $0.6-0.8$, protein expression was induced with $0.2 \%$ arabinose and cells were grown for additional $16 \mathrm{~h}$ at $16^{\circ} \mathrm{C}$. Next, the cells were pelleted by centrifugation, resuspended in $20 \mathrm{mM}$ Tris- $\mathrm{HCl}\left(\mathrm{pH} 8.0\right.$ at $\left.25^{\circ} \mathrm{C}\right), 500 \mathrm{mM} \mathrm{NaCl}$, $5 \mathrm{mM}$ 2-mercaptoethanol, $25 \mathrm{mM}$ imidazole, $2 \mathrm{mM} \mathrm{PMSF}$ and $5 \%(\mathrm{v} / \mathrm{v})$ glycerol-containing buffer and disrupted by sonication. The supernatant obtained after centrifugation was loaded onto the $\mathrm{Ni}^{2+}$-charged HiTrap chelating HP column (GE Healthcare) and bound proteins were eluted with a linear gradient of increasing imidazole concentration from $25 \mathrm{mM}$ to $500 \mathrm{mM}$ in $20 \mathrm{mM}$ Tris- $\mathrm{HCl}$ (pH 8.0 at $25^{\circ} \mathrm{C}$ ), $500 \mathrm{mM}$ $\mathrm{NaCl}, 5 \mathrm{mM}$ 2-mercaptoethanol and $5 \%(\mathrm{v} / \mathrm{v})$ glycerol buffer. The fractions containing TnpB RNP complexes were pooled and the $6 \times$ His-MBP tag was cleaved by overnight incubation with TEV protease at $8^{\circ} \mathrm{C}$. Next, the reaction mixture was loaded onto the StrepTrap column (GE Healthcare), washed with $20 \mathrm{mM}$ Tris- $\mathrm{HCl}\left(\mathrm{pH} 8.0\right.$ at $\left.25^{\circ} \mathrm{C}\right), 150 \mathrm{mM}$ $\mathrm{NaCl}, 5 \mathrm{mM}$ 2-mercaptoethanol and $5 \%(\mathrm{v} / \mathrm{v})$ glycerol buffer and bound TnpB complex eluted with $2.5 \mathrm{mM} d$-desthiobiotin solution. Fractions containing TnpB RNP were pooled, loaded on a HiTrap heparin HP column (GE Healthcare) and eluted using a linear gradient of increasing $\mathrm{NaCl}$ concentration from $0.15 \mathrm{M}$ to $1.0 \mathrm{M}$. Obtained TnpB RNP complex fractions were pooled, concentrated up to $0.5 \mathrm{ml}$ using the Amicon Ultra-15 centrifugal filter unit (Merck Millipore) and loaded on a Superdex $20010 / 300 \mathrm{GL}$ (GE Healthcare) gel filtration column equilibrated with $20 \mathrm{mM}$ Tris- $\mathrm{HCl}\left(\mathrm{pH} 8.0\right.$ at $\left.25^{\circ} \mathrm{C}\right), 250 \mathrm{mM} \mathrm{NaCl}$ and $5 \mathrm{mM}$ 2-mercaptoethanol buffer. Peak fractions containing TnpB RNP complexes were pooled and dialysed against $20 \mathrm{mM}$ Tris- $\mathrm{HCl}(\mathrm{pH} 8.0$ at $\left.25^{\circ} \mathrm{C}\right), 250 \mathrm{mM} \mathrm{NaCl}, 2 \mathrm{mM} \mathrm{DTT}$ and $50 \%(\mathrm{v} / \mathrm{v})$ glycerol-containing buffer and stored at $-20^{\circ} \mathrm{C}$. The concentration of the TnpB RNP complex was determined by quantifying the intensity of protein bands in SDS-PAGE gels and comparing them to the protein standard of known concentration. The sequences of TnpB protein constructs are listed in Supplementary Table 2 .

\section{Molecular mass measurements by mass photometry}

Measurement coverslips (no. $1.5 \mathrm{H}, 24 \times 50 \mathrm{~mm}$; Marienfeld) were cleaned by sequential sonication for $5 \mathrm{~min}$ in MilliQ water, isopropanol and MilliQ water and then dried using a clean stream of nitrogen gas. A prepared coverslip was mounted onto the OneMP mass photometer (Refeyn) and a CultureWell Reusable Gasket (Grace Bio-Labs) was

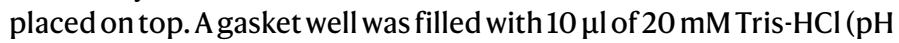
8.0 at $25^{\circ} \mathrm{C}$ ) and $250 \mathrm{mM} \mathrm{NaCl}$ buffer, $10 \mu \mathrm{l}$ of the diluted TnpB RNP complex sample (approximately $60 \mathrm{nM}$ ) was added and the adsorption of biomolecules was monitored for $120 \mathrm{~s}$ using the AcquireMP software (Refeyn). For converting the measured ratiometric contrast into molecular mass, Un1Cas12f1 protein ${ }^{19}$ and its oligomers ranging from $60 \mathrm{kDa}$ to $250 \mathrm{kDa}$ (monomer to tetramer) were used for calibration. Samples were measured in triplicates. Mass photometry movies were analysed using DiscoverMP (Refeyn).

\section{Extraction and analysis of TnpB-bound nucleic acids}

To extract TnpB-bound nucleic acids, $100 \mu$ l of purified TnpB samples was incubated with $5 \mu \mathrm{l}(20 \mathrm{mg} / \mathrm{ml})$ of proteinase $\mathrm{K}$ (Thermo Fisher Scientific) for $45 \mathrm{~min}$ at $37^{\circ} \mathrm{C}$ in $1 \mathrm{ml}$ of $10 \mathrm{mM} \mathrm{Tris}-\mathrm{HCl}\left(\mathrm{pH} 7.5\right.$ at $\left.37^{\circ} \mathrm{C}\right)$, $5 \mathrm{mM} \mathrm{MgCl}_{2}, 100 \mathrm{mM} \mathrm{NaCl}, 1 \mathrm{mM}$ DTT and $1 \mathrm{mM}$ EDTA reaction buffer. Next, the mixtures were treated with phenol:chloroform:isoamyl alcohol (25:24:1) solution and the aqueous phase was subsequently mixed with chloroform to remove any remaining phenol. The solution with nucleic acids was split into fresh tubes (198 $\mu$ into each) and incubated with $2 \mu \mathrm{l}$ of RNase I $(10 \mathrm{U} / \mu \mathrm{l})$ (Thermo Fisher Scientific) or DNase I $(10 \mathrm{U} / \mu \mathrm{l})$ (Thermo Fisher Scientific) for $45 \mathrm{~min}$ at $37^{\circ} \mathrm{C}$. Reaction products were mixed with $2 \times$ RNA loading dye (Thermo Fisher Scientific), separated on TBE-Urea $(8 \mathrm{M}) 15 \%$ denaturing polyacrylamide gel using $0.5 \times$ TBE electrophoresis buffer (Thermo Fisher Scientific) and visualized with SYBR Gold (Thermo Fisher Scientific). 


\section{RNA isolation from the TnpB RNP complex}

For TnpB-bound RNA extraction, $100 \mu$ l of purified TnpB complex was incubated with $5 \mu \mathrm{l}(20 \mathrm{mg} / \mathrm{ml})$ of proteinase $\mathrm{K}$ (Thermo Fisher Scientific) for $45 \mathrm{~min}$ at $37^{\circ} \mathrm{C}$ in $1 \mathrm{ml}$ of $10 \mathrm{mM} \mathrm{Tris}-\mathrm{HCl}\left(\mathrm{pH} 7.5\right.$ at $\left.37^{\circ} \mathrm{C}\right), 5 \mathrm{mM}$ $\mathrm{MgCl}_{2}, 100 \mathrm{mM} \mathrm{NaCl}, 1 \mathrm{mM}$ DTT and $1 \mathrm{mM}$ EDTA reaction buffer. DNA was removed by adding $10 \mu \mathrm{l}$ of DNase $\mathrm{I}(10 \mathrm{U} / \mu \mathrm{l})$ (Thermo Fisher Scientific) and incubating for an additional $45 \mathrm{~min}$ at $37^{\circ} \mathrm{C}$, and the reaction mixture was purified with a GeneJET RNA Cleanup and Concentration Micro Kit (Thermo Fisher Scientific). Next, $3 \mu \mathrm{g}$ of purified RNAs was phosphorylated at $37^{\circ} \mathrm{C}$ for 30 min using $1 \mu \mathrm{l}(10 \mathrm{U} / \mu \mathrm{l})$ of PNK (Thermo Fisher Scientific) in $1 \times$ reaction buffer A (Thermo Fisher Scientific) supplemented with $1 \mathrm{mM}$ ATP $(20 \mu \mathrm{l}$ reaction volume $)$. Reaction products were purified using a GeneJET RNA Cleanup and Concentration Micro Kit (Thermo Fisher Scientific).

\section{RNA sequencing and analysis}

RNA libraries were prepared using Collibri Stranded RNA Library Prep Kit for Illumina Systems (Thermo Fisher Scientific) according to the manufacturer's instructions for small RNAs (protocol MAN0025359), pooled in an equimolar ratio and pair-end sequenced $(2 \times 75 \mathrm{bp})$ using MiSeq Reagent Kit v2, 300 cycles (Illumina) on a MiSeq System (Illumina). The pair-end reads shorter than $20 \mathrm{bp}$ were filtered with Cutadapt $^{34}$. The remaining reads were mapped to the transposon-encoding plasmid (pTWIST-ISDra2; Supplementary Table 1) using BWA ${ }^{35}$ and converted to the BAM file format with SAMtools ${ }^{36}$. The resulting coverage data were visualized using Integrative Genomics Viewer ${ }^{37}$.

\section{TnpB cleavage of plasmid DNA library}

For dsDNA cleavage detection and TAM characterization, the previously developed PAM determination assay for Cas9 and Cas12 effectors was adopted ${ }^{19,38,39}$. In brief, the tnpB gene and reRNA constructs, targeting 16-bp or 20-bp sequences in the plasmid library pTZ57 (Supplementary Table 1), adjacent to a $7 \mathrm{~N}$ randomized region (Supplementary Table 3), were cloned into a pETDuet-1 (Millipore Sigma) vector (pGB77-78; Supplementary Table 1). Next, E. coli ArcticExpress (DE3) cells were transformed with TnpB RNP components encoding plasmids and the cells were grown in LB medium supplemented with ampicillin $(100 \mu \mathrm{g} / \mathrm{ml})$ and gentamicin $(10 \mu \mathrm{g} / \mathrm{ml})$. After reaching an $\mathrm{OD}_{600}$ of 0.5 , TnpB expression was induced with $0.5 \mathrm{mM}$ IPTG and the culture was incubated overnight at $16^{\circ} \mathrm{C}$. The cells from $10 \mathrm{ml}$ of overnight culture were collected by centrifugation, resuspended in $1 \mathrm{ml}$ of lysis buffer (20 mM phosphate ( $\mathrm{pH} 7.0), 0.5 \mathrm{M} \mathrm{NaCl}, 5 \%(\mathrm{v} / \mathrm{v})$ glycerol and $2 \mathrm{mM}$ PMSF) and lysed by sonication. Cell debris was removed by centrifugation, and $10 \mu$ l of the obtained TnpB RNPs containing supernatant were used directly in the digestion experiments. In brief, lysate was mixed with $1 \mu \mathrm{g}$ of the $7 \mathrm{~N}$ randomized plasmid library (approximately $20 \mathrm{M}$ fold coverage of all 7 N TAM sequences) in $100 \mu \mathrm{l}$ of reaction buffer $\left(10 \mathrm{mM}\right.$ Tris- $\mathrm{HCl}\left(\mathrm{pH} 7.5\right.$ at $\left.37^{\circ} \mathrm{C}\right), 100 \mathrm{mM} \mathrm{NaCl}, 1$ $\mathrm{mM} \mathrm{DTT}$ and $10 \mathrm{mM} \mathrm{MgCl}$ ) and incubated for $1 \mathrm{~h}$ at $37^{\circ} \mathrm{C}$. Cleaved DNA ends were repaired by adding $1 \mu$ l of T4 DNA polymerase (Thermo Fisher Scientific), $1 \mu \mathrm{l}$ of $10 \mathrm{mM}$ dNTP mix (Thermo Fisher Scientific) and incubating at $11^{\circ} \mathrm{C}$ for $20 \mathrm{~min}$, followed by heating the mix up to $75^{\circ} \mathrm{C}$ for $10 \mathrm{~min}$. Next, $3^{\prime}$-dA overhangs were added by incubating the reaction mixture with $1 \mu$ l of DreamTaq polymerase (Thermo Fisher Scientific) and $1 \mu \mathrm{l}$ of $10 \mathrm{mM}$ dATP (Thermo Fisher Scientific) for $30 \mathrm{~min}$ at $72{ }^{\circ} \mathrm{C}$. In addition, RNA was removed by incubating for $15 \mathrm{~min}$ at $37^{\circ} \mathrm{C}$ with $1 \mu$ l of RNase A (Thermo Fisher Scientific) and the DNA was purified using the GeneJet PCR Purification Kit (Thermo Fisher Scientific). The purified cleavage products $(100 \mathrm{ng})$ were ligated with a dsDNA adapter containing a $3^{\prime}$-dT overhang (100 ng) for $1 \mathrm{~h}$ at $22^{\circ} \mathrm{C}$ using $1 \mu$ l of T4 DNA ligase (Thermo Fisher Scientific) in $20 \mu$ reaction volume. Next, the adapter-bearing cleavage products were PCR amplified and gel purified using the GeneJet Gel Purification Kit (Thermo Fisher Scientific). DNA libraries were prepared using the Collibri PS
DNA Library Prep Kit for Illumina Systems (Thermo Fisher Scientific) according to the manufacturer's instructions, pooled in an equimolar ratio and pair-end sequenced $(2 \times 150 \mathrm{bp})$ using MiSeq Reagent Kit v2, 300 cycles (Illumina) on a MiSeq System (Illumina).

dsDNA target cleavage by the TnpB RNP complex was evaluated by examining the adapter ligation at the targeted sequence in the $7 \mathrm{~N}$ plasmid library. This was accomplished by extracting and counting all reads containing the adapter ligated at the $0-30 \mathrm{bp}$ target positions next to the $7 \mathrm{~N}$ region and identifying $10 \mathrm{bp}$ of perfectly matching sequences derived from the adapter and the plasmid backbone. The analysis revealed that $1-5 \%$ of total reads have the adapter ligated at the 0-30-bp target positions. The reads exhibiting elevated frequency of adapter ligation in the target region (20-21 bp from the $7 \mathrm{~N}$ randomized sequence) were used for $7 \mathrm{~N}$ sequence (TAM) extraction and representation in WebLogo ${ }^{40}$ and position frequency matrix (PFM) formats. The Python scripts used in the cleavage position identifications and TAM characterization are provided in the GitHub repository (https://github. com/tkarvelis/Nuclease_manuscript).

\section{DNA substrates}

Plasmid DNA substrates used in in vitro cleavage assays (pGB72-73) were obtained by cloning oligoduplexes assembled after annealing complementary synthetic oligonucleotides (Thermo Fisher Scientific) into the pSG4K5 plasmid (a gift from X. Wang, Addgene plasmid \#74492) pre-cleaved with EcoRI and Nhel restriction endonucleases (Thermo Fisher Scientific). The links to the plasmid sequences are provided in Supplementary Table 1 and the targeted sequences are provided in Supplementary Table 3.

Synthetic DNA substrates were 5 ' end labelled by incubating $1 \mu \mathrm{M}$ of oligonucleotide (Thermo Fisher Scientific) with $1 \mu \mathrm{l}(10 \mathrm{U} / \mu \mathrm{l})$ of PNK (Thermo Fisher Scientific) and ${ }^{32} \mathrm{P}-\gamma$-ATP (PerkinElmer) at $37^{\circ} \mathrm{C}$ for $30 \mathrm{~min}$ in $7.5 \mu \mathrm{l}$ of $1 \times$ reaction buffer A (Thermo Fisher Scientific). Oligoduplexes $(100 \mathrm{nM})$ were obtained by combining ${ }^{32} \mathrm{P}$-labelled and unlabelled complementary oligonucleotides (1:1.5 molar ratio) followed by heating to $95^{\circ} \mathrm{C}$ and slow cooling to room temperature. The sequences of the substrates are provided in Supplementary Table 2.

\section{DNA cleavage assays}

Plasmid DNA cleavage reactions were initiated by mixing $100 \mathrm{nM}$ of TnpB RNP complex with $3 \mathrm{nM}$ of plasmid DNA (pGB72-73; Supplementary Table 1$)$ in $10 \mathrm{mM}$ Tris- $\mathrm{HCl}\left(\mathrm{pH} 7.5\right.$ at $\left.37^{\circ} \mathrm{C}\right), 10 \mathrm{mM} \mathrm{MgCl}_{2}, 1 \mathrm{mMDTT}$, $1 \mathrm{mMEDTA}$ and $100 \mathrm{mM} \mathrm{NaCl}$ reaction buffer and incubating at $37^{\circ} \mathrm{C}$ for $60 \mathrm{~min}$. The reactions were quenched by adding $3 \times$ loading dye solution $(0.03 \%$ bromophenol blue, $0.3 \%$ SDS and 75 mM EDTA in $30 \%(v / v)$ glycerol) and analysed by agarose gel electrophoresis and ethidium bromide staining. The linearized plasmid substrate was obtained by pre-cleaving target plasmid with Ndel endonuclease (Thermo Fisher Scientific).

Cleavage reactions with synthetic oligoduplexes (Supplementary Table 4) were initiated by combining $100 \mathrm{nM}$ TnpB RNP complex with $1 \mathrm{nM}$ radiolabelled substrate in $100 \mu \mathrm{l}$ of $10 \mathrm{mM}$ Tris- $\mathrm{HCl}\left(\mathrm{pH} 7.5\right.$ at $\left.37^{\circ} \mathrm{C}\right)$, $10 \mathrm{mM} \mathrm{MgCl}_{2}, 1 \mathrm{mMDTT}, 1 \mathrm{mMEDTA}$ and $100 \mathrm{mM} \mathrm{NaCl}$ reaction buffer at $37^{\circ} \mathrm{C}$. Aliquots of $10 \mu \mathrm{l}$ were removed from the reaction mixture at timed intervals ( $0 \mathrm{~min}, 1 \mathrm{~min}, 5 \mathrm{~min}, 15 \mathrm{~min}$ and $60 \mathrm{~min}$ ), quenched with $1.8 \times$ volume of a loading dye $(95 \%(\mathrm{v} / \mathrm{v})$ formamide, $0.01 \%$ bromophenol blue and $25 \mathrm{mMEDTA}$ ) and subjected to denaturing gel electrophoresis ( $20 \%$ polyacrylamide containing $8.5 \mathrm{M}$ urea in $0.5 \times \mathrm{TBE}$ buffer).

\section{Plasmid interference assay}

Plasmid interference assays were performed in the $E$. coli Arctic Express (DE3) strain bearing TnpB and reRNA encoding plasmids (pGB74-76) (Supplementary Table 1). The cells were grown at $37^{\circ} \mathrm{C}$ to an $\mathrm{OD}_{600}$ of approximately 0.5 and electroporated with $100 \mathrm{ng}$ of a target-containing plasmid engineered from pSG4K5 (a gift from X. Wang, Addgene plasmid 74492) (pGB72; Supplementary Table1). After 
1 h, co-transformed cells were further diluted by serial of $10 \times$ fold dilutions and grown at $25^{\circ} \mathrm{C}$ on plates containing IPTG $(0.1 \mathrm{mM})$, gentamicin $(10 \mu \mathrm{g} / \mathrm{ml})$, carbenicillin $(100 \mu \mathrm{g} / \mathrm{ml})$ and kanamycin $(50 \mu \mathrm{g} / \mathrm{ml})$ for $44 \mathrm{~h}$.

\section{HEK293T cell culturing and genome editing}

HEK293T cells purchased from the American Type Culture Collection (catalogue number CRL-3216) were cultivated in DMEM (Gibco) supplemented with $10 \% \mathrm{FBS}$ (Gibco), penicillin $(100 \mathrm{U} / \mathrm{ml})$ and streptomycin $(100 \mu \mathrm{g} / \mathrm{ml})$ (Thermo Fisher Scientific). The cell line was not further authenticated and was not tested for mycoplasma contamination. A day before transfection, the cells were plated in a 24-well plate at a density of $1.4 \times 10^{5}$ cells per well. The transfection mixture was prepared by mixing $1 \mu \mathrm{g}$ of plasmid encoding NLS-tagged TnpB and its reRNA (pRZ122-127; Supplementary Table 1) with $2 \mu$ of TurboFect transfection reagent (Thermo Fisher Scientific) in $100 \mu$ l of serum-free DMEM. After 15 min of incubation at room temperature, the transfection mix was added dropwise to the cells. The cells were then grown for $72 \mathrm{~h}$ at $37^{\circ} \mathrm{C}$ and $5 \% \mathrm{CO}_{2}$.

\section{Indel characterization}

Transfected HEK293T cells were trypsinized, washed and resuspended in $100 \mu$ l of PBS (approximately $6 \times 10^{5}$ cells were collected from each well), and $10 \mu \mathrm{l}$ of the obtained suspension was lysed using $50 \mu \mathrm{l}$ of QuickExtract solution (Lucigen). Next, two rounds of PCR were performed: first to amplify the DNA region surrounding each target site, and second to add the sequences required for Illumina sequencing and indexing. In brief, 1-4 $\mu$ l of cell lysate was used in the primary PCR with primers specific to the targeted genomic locus that were $5^{\prime}$ tailed with Illumina Read1 and Read 2 sequences, in a final volume of $20 \mu \mathrm{l}$, using Hot Start Phusion Polymerase (Thermo Fisher Scientific). The thermocycler setting consisted of initial denaturation at $98^{\circ} \mathrm{C}$ for $30 \mathrm{~s}, 15$ cycles of $98^{\circ} \mathrm{C}$ for $15 \mathrm{~s}, 56.8^{\circ} \mathrm{C}$ for $15 \mathrm{~s}, 72^{\circ} \mathrm{C}$ for $30 \mathrm{~s}$, and final incubation at $72^{\circ} \mathrm{C}$ for $5 \mathrm{~min}$. The resulting amplicons were cleaned using $1.8 \times$ volume of magnetic beads (Lexogen) and eluted in $30 \mu \mathrm{l}$ of elution buffer. Of the eluted mixture, $6 \mu \mathrm{l}$ was used as a template for the second round of PCR, in a final volume of $30 \mu \mathrm{l}$, to index and add $\mathrm{P} 5$ and $\mathrm{P} 7$ adapters required for Illumina sequencing, using the Lexogen PCR Add on Kit (Lexogen) with the i7 $6 \mathrm{nt}$ Index Set (Lexogen). The thermocycler setting consisted of initial denaturation at $98^{\circ} \mathrm{C}$ for $30 \mathrm{~s}, 15$ cycles of $98^{\circ} \mathrm{C}$ for $10 \mathrm{~s}, 65^{\circ} \mathrm{C}$ for $20 \mathrm{~s}, 72^{\circ} \mathrm{C}$ for $30 \mathrm{~s}$ and final incubation at $72{ }^{\circ} \mathrm{C}$ for $1 \mathrm{~min}$. To ensure the purity of the PCR products, an additional cleanup with $0.9 \times$ volume of magnetic beads (Lexogen) was performed. Barcoded and purified DNA samples were quantified by Qubit 4 Fluorometer (Thermo Fisher Scientific), analysed using BioAnalyzer (Agilent), pooled in an equimolar ratio and pair-end sequenced $(2 \times 75 \mathrm{bp})$ using the MiniSeq High Output Reagent Kit, 150 cycles (Illumina) on a MiniSeq System (Illumina). Indels were analysed using CRISPResso 2 with the following parameters: minimum of $70 \%$ homology for alignment to the amplicon sequence, quantification window of $10 \mathrm{bp}$, ignoring substitutions to avoid false positives and phred33 score of more than 10 for average read and single base pair quality ${ }^{41}$. The primers and target sequences are provided in Supplementary Tables 5 and 6, respectively.

\section{ISDra2 TnpB modelling and structure comparison}

To gain insight into the structure of TnpB, we submitted separately $\mathrm{N}$-terminal and $\mathrm{C}$-terminal regions to the well-performing publicly available structure prediction servers trRosetta ${ }^{42}$, tFOLD (https://drug. ai.tencent.com) and Raptor $X^{43}$, as established by CASP (Critical Assessment of Protein Structure Prediction). All three methods returned very similar structures for either $\mathrm{N}$-terminal or $\mathrm{C}$-terminal region. As expected, the $\mathrm{C}$-terminal region features the RuvC domain with the inserted zinc-finger domain. The structure of the modelled $\mathrm{N}$-terminal region corresponded to $\mathrm{\beta} \beta$-barrel domain with the inserted three-helix bundle. A search with the trRosetta model of the $\mathrm{N}$-terminal region of
TnpB against the Protein Data Bank using Dali ${ }^{44}$ identified $\mathrm{N}$-terminal lobes of other Cas 12 proteins as the closest matches. The TnpB $\beta$-barrel matched a similar domain in Cas12, often referred to as the 'Wedge' domain, whereas the inserted helical bundle matched a part of the 'Rec' domain. More detailed structural comparison with available different Cas12 groups revealed that the $\mathrm{N}$-terminal region of $\mathrm{TnpB}$ corresponds to the minimal common structural elements present in Cas12. The TnpB RuvC region also represents a streamlined version of Cas12 RuvC domain variants. Most recently, as the highly accurate AlphaFold2 structure prediction method ${ }^{45}$ became publicly available, we sought further investigation of the TnpB structure. AlphaFold2 produced TnpB models that were very similar to those obtained previously, suggesting that the predicted TnpB structure might be fairly accurate.

\section{Statistics and reproducibility}

All experiments represented without replicates (for example, gels for qualitative characterization of proteins and nucleic acids) have been reproduced at least three times independently (except for the small RNA sequencing and plasmid library cleavage experiments, which were performed once).

\section{Reporting summary}

Further information on research design is available in the Nature Research Reporting Summary linked to this paper.

\section{Data availability}

All data are available in the paper and the supplementary material. In addition, small RNA and plasmid library cleavage sequencing data are available on the NCBI Sequence Read Archive under BioProject ID PRJNA723137. The ISfinder database was accessed at https://isfinder. biotoul.fr.

\section{Code availability}

The Python scripts used for identification of the plasmid library cleavage positions and characterization of TAMs are available in a GitHub repository found at https://github.com/tkarvelis/Nuclease_manuscript.

34. Martin, M. Cutadapt removes adapter sequences from high-throughput sequencing reads. EMBnet.journal 17, 10-12 (2011).

35. Li, H. \& Durbin, R. Fast and accurate long-read alignment with Burrows-Wheeler transform. Bioinformatics 26, 589-595 (2010).

36. Li, H. et al. The Sequence Alignment/Map format and SAMtools. Bioinformatics 25, 2078-2079 (2009).

37. Robinson, J. T. et al. Integrative genomics viewer. Nat. Biotechnol. 29, 24-26 (2011).

38. Karvelis, T. et al. Rapid characterization of CRISPR-Cas9 protospacer adjacent motif sequence elements. Genome Biol. 16, 253 (2015).

39. Karvelis, T., Young, J. K. \& Siksnys, V. A pipeline for characterization of novel Cas9 orthologs. Methods Enzymol. 616, 219-240 (2019).

40. Crooks, G. E. WebLogo: a sequence logo generator. Genome Res. 14, 1188-1190 (2004).

41. Clement, K. et al. CRISPResso2 provides accurate and rapid genome editing sequence analysis. Nat. Biotechnol. 37, 224-226 (2019).

42. Yang, J. et al. Improved protein structure prediction using predicted interresidue orientations. Proc. Natl Acad. Sci. USA 117, 1496-1503 (2020).

43. $\mathrm{Xu}, \mathrm{J}$. Distance-based protein folding powered by deep learning. Proc. Natl Acad. Sci. USA 116, 16856-16865 (2019).

44. Holm, L. in Structural Bioinformatics: Methods and Protocols (ed. Gáspári, Z.) 29-42 (Springer US, 2020).

45. Jumper, J. et al. Highly accurate protein structure prediction with AlphaFold. Nature $\mathbf{9 6 ,}$ 583-589 (2021).

Acknowledgements We thank Ž. Kapustina for small RNA sequencing, S. Henkel-Heinecke and R. Seidel for performing mass photometry experiments, and S. Halford for the comments and critical reading of the manuscript. Research was supported by a Novozyme Prize grant to V.S.

Author contributions T.K. and V.S. designed the research. T.K., G.D., G.B. and A.S. performed the protein purifications. T.K. and K.B. carried out RNA purification for small RNA sequencing, plasmid library cleavage and DNA interference in E. coli experiments. G.D. and G.B. performed 


\section{Article}

the DNA cleavage experiments in vitro. T.K., G.B. and R.Z. performed the genome editing experiments. D.K. and C.V. were involved in sequence and structure analyses. T.K. and V.S. wrote the manuscript with input from all authors. All authors read and approved the final manuscript.

Competing interests T.K. and V.S. are co-inventors on a patent application (PCT/

IB2021/055958) filed by Vilnius University relating to the work described in this paper. V.S. is a

chairman of and has financial interest in CasZyme.
Additional information

Supplementary information The online version contains supplementary material available at https://doi.org/10.1038/s41586-021-04058-1.

Correspondence and requests for materials should be addressed to Tautvydas Karvelis or

Virginijus Siksnys.

Peer review information Nature thanks Martin Jinek and the other, anonymous, reviewer(s) for their contribution to the peer review of this work.

Reprints and permissions information is available at http://www.nature.com/reprints. 
a

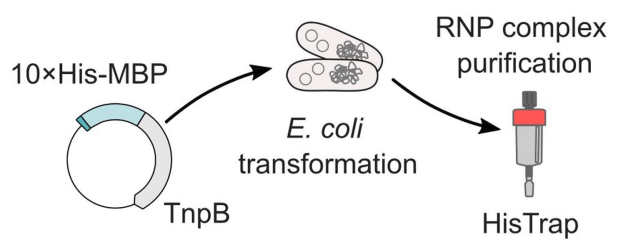

Elution fractions of "TnpB" (95.4 kDa)

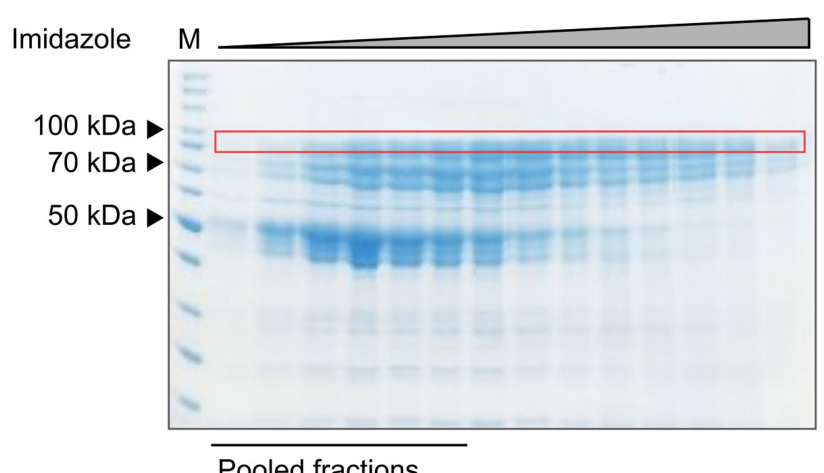

C

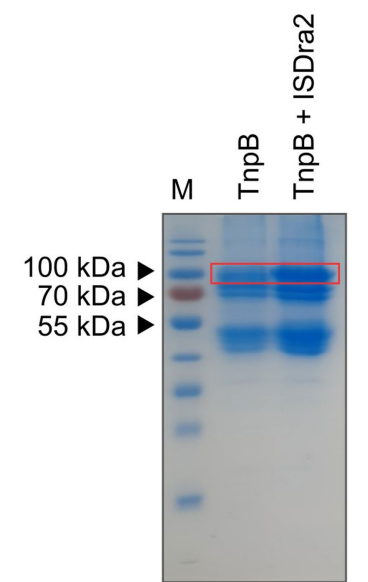

d b

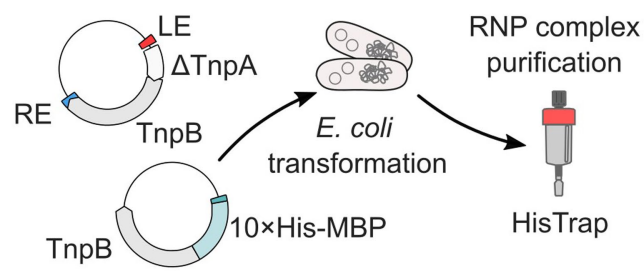

Elution fractions of "TnpB + ISDra2"

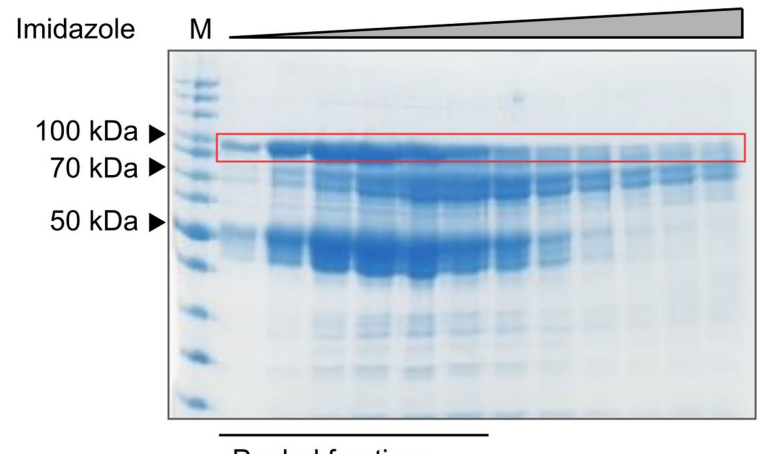

Pooled fractions
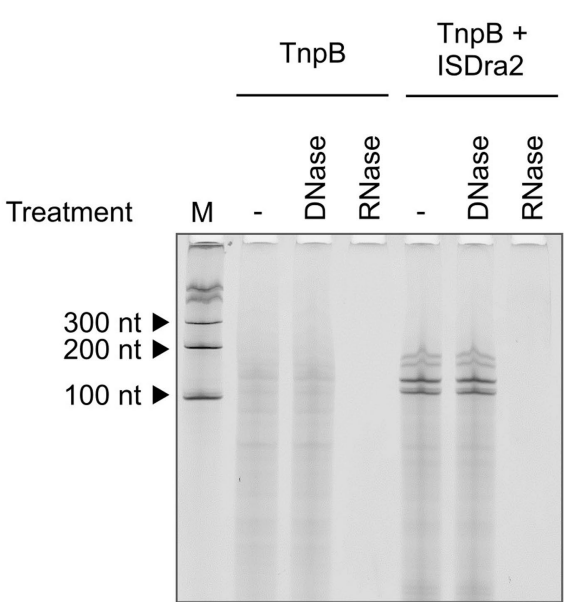

Extended Data Fig. 1 | Purification of ISDra2 TnpB. a, b, Experimental workflow for expression and purification of a single TnpB (a) and TnpB co-expressed with ISDra2 ( $\triangle \mathrm{TnpA})(\mathbf{b})$ in $E$. coli cells. SDS-PAGE gels show elution fractions of proteins bound to HisTrap chelating column. Red boxes denote bands corresponding to an intact $10 \times \mathrm{MBP}-\mathrm{TnpB}$ protein $(95.4 \mathrm{kDa})$. c, SDS-PAGE gel of pooled fractions indicated in $\mathbf{a}$ and $\mathbf{b}$. d, Detection and analysis of nucleic acids co-purifying with $\mathrm{TnpB}$ protein. For uncropped gel images, see Supplementary Fig. 2. 
Article

a

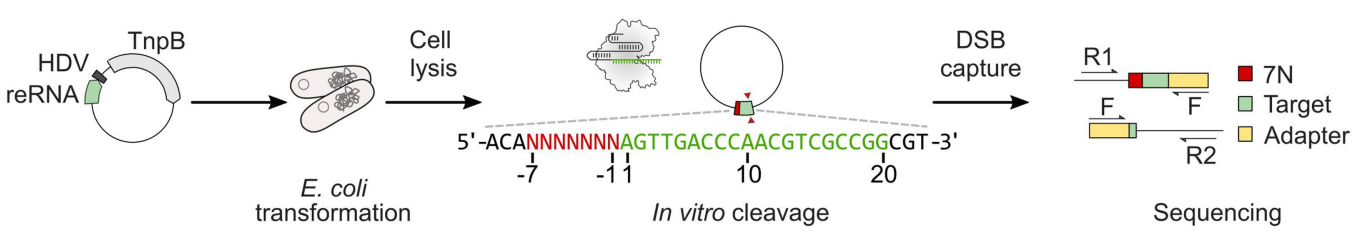

b

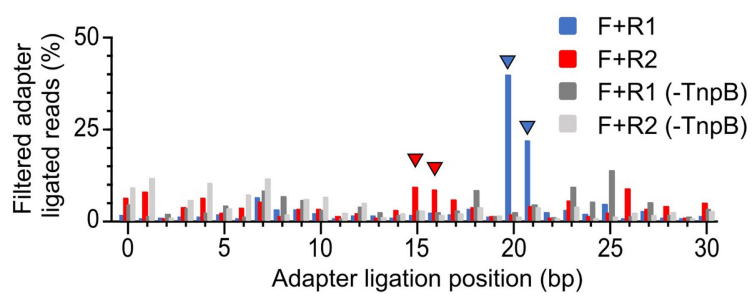

Extended Data Fig. 2 | TnpB RNP complex cleaves dsDNA in a TAM dependent manner. a, Experimental workflow of double-stranded (As) DNA cleavage activity detection. The eRNA encoding construct contained $20 \mathrm{nt}$ guide sequence. $\mathrm{F}$ - forward primer, annealing to ligated adapter. R1 and R2 reverse primers, annealing to the plasmid backbone. $7 \mathrm{~N}$ represents the randomized region in the plasmid library next to the targeted sequence. c

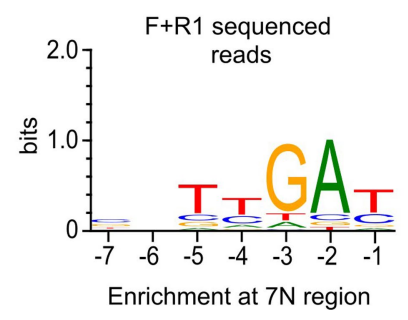

d

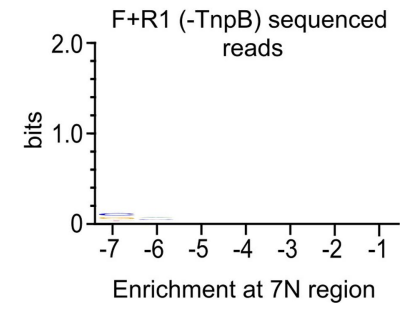

b, Adapter ligation position determination indicating double-stranded break (DSB) formation in the targeted sequence. “-TnpB” represents the cleavage reactions using lysates obtained from the cells that do not express TnpB. c, d, WebLog representation of motifs identified in $7 \mathrm{~N}$ randomized region at 20-21 bp F + R1 and F + R1 (-TnpB) enriched adapter ligated reads, respectively. No substantial enrichment is observed at $7 \mathrm{~N}$ region for “-TnpB" reactions. 
a

\begin{tabular}{|c|c|c|c|c|c|c|c|}
\hline & \multicolumn{7}{|c|}{ TAM position } \\
\hline & -7 & -6 & -5 & -4 & -3 & -2 & -1 \\
\hline A & 0.12 & 0.33 & 0.08 & 0.14 & 0.08 & 0.80 & 0.08 \\
\hline & 0.40 & 0.24 & 0.15 & 0.28 & 0.03 & 0.09 & 0.26 \\
\hline G & 0.29 & 0.15 & 0.14 & 0.07 & 0.79 & 0.05 & 0.08 \\
\hline$T$ & 0.20 & 0.28 & 0.63 & 0.52 & 0.10 & 0.05 & 0.58 \\
\hline & $\mathrm{N}$ & $\mathrm{N}$ & $\mathrm{T}$ & $\mathrm{T}$ & G & $A$ & $\mathrm{~T}$ \\
\hline
\end{tabular}

$\mathrm{F}+\mathrm{R} 1$ sequenced reads (TnpB with $16 \mathrm{nt}$ guide) b

\begin{tabular}{|c|c|c|c|c|c|c|c|}
\hline & & & & & & & \\
\hline & -7 & -6 & -5 & -4 & -3 & -2 & -1 \\
\hline & 0.11 & 0.33 & 0.07 & 0.13 & 0.08 & 0.82 & 0.08 \\
\hline & 0.39 & 0.23 & 0.15 & 0.26 & 0.03 & 0.08 & 0.25 \\
\hline G & 0.30 & 0.15 & 0.13 & 0.07 & 0.80 & 0.06 & 0.08 \\
\hline & 0.20 & 0.28 & 0.65 & 0.54 & 0.10 & 0.05 & 0.59 \\
\hline & $\mathrm{N}$ & $\mathrm{N}$ & $\mathrm{T}$ & $\mathrm{T}$ & $G$ & $A$ & $\mathrm{~T}$ \\
\hline
\end{tabular}

C

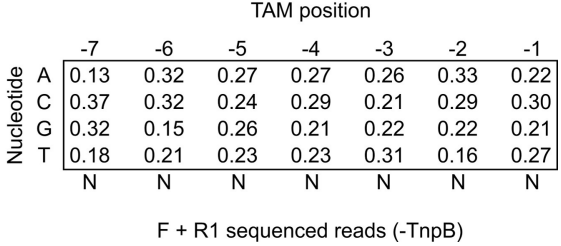

Extended Data Fig. 3 | Position frequency matrix (PFM) of the nucleotides at $7 \mathrm{~N}$ region obtained after plasmid library cleavage using $E$. coli lysates. a, b, PFM representation of nucleotides distribution identified in $7 \mathrm{~N}$ randomized region at $20-21 \mathrm{bp} \mathrm{F}+\mathrm{R} 1$ enriched adapter ligated reads obtained from $E$. coli cells expressing TnpB and reRNA constructs with $16 \mathrm{nt}$ and $20 \mathrm{nt}$ guide sequences, respectively. $c$, the cleavage reaction using lysate obtained from the cells that do not express TnpB demonstrates no substantial enrichment of motifs at $7 \mathrm{~N}$ region. 


\section{Article}

a

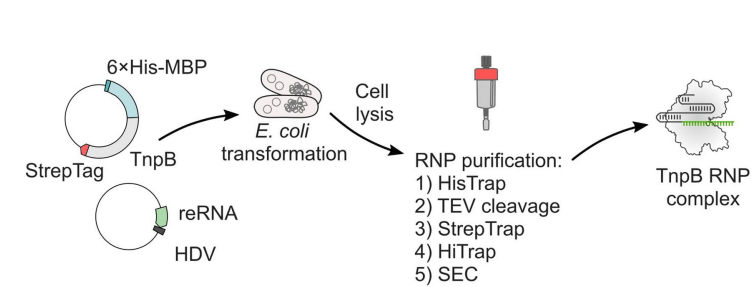

b

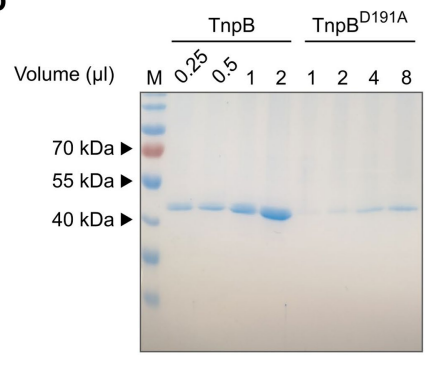

C

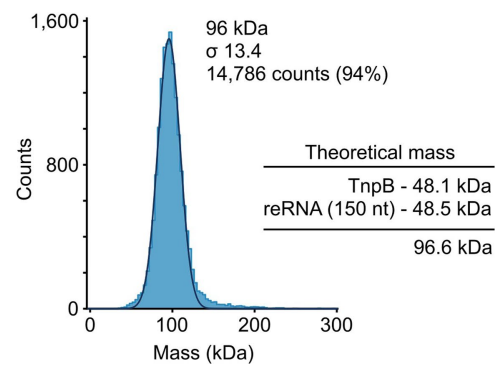

Extended Data Fig. 4 | TnpB RNP complex purification. a, Experimental workflow of TnpB RNP complex expression and multi-step purification. The reRNA encoding construct contained a 16 nt guide sequence and carried an HDV ribozyme sequence at the 3'-end, which enabled production of the reRNA with fixed $16 \mathrm{nt}$ length guide sequence. $\mathbf{b}$, SDS-PAGE analysis of the purified
TnpB and TnpB (D191A) RNP complexes. For uncropped gel image, see Supplementary Fig. 2. c, Molecular mass of TnpB and reRNA RNP complex determined by mass photometry. Experimentally established molecular mass corresponds to TnpB RNP complex consisting of a TnpB protein monomer bound to a $\sim 150 \mathrm{nt}$ long reRNA in a 1:1 molar ratio. 
a

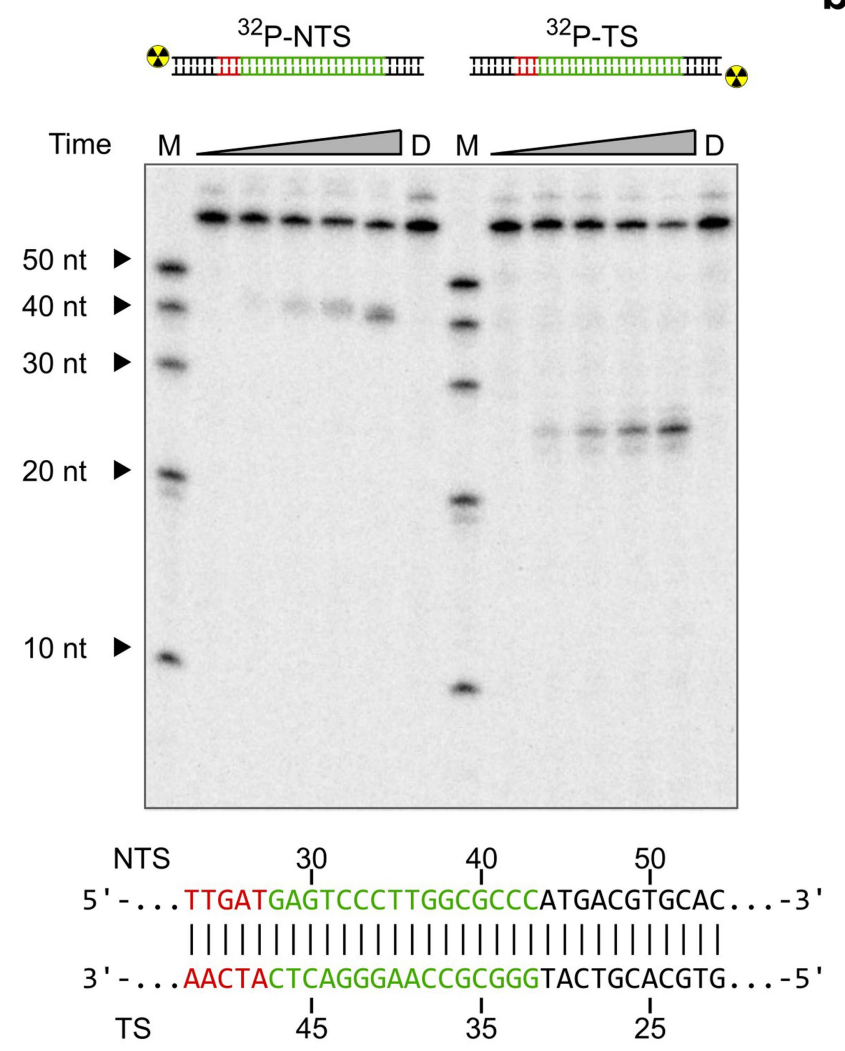

Extended Data Fig. 5 | Synthetic dsDNA cleavage by TnpB RNP complex. $\mathbf{a}, \mathbf{b}$, Cleavage of dsDNA substrates containing a target (represented in green colour) with TAM (red colour) (a) or without TAM sequence (b). TnpB RNP complex cleaves dsDNA in a TAM-dependent manner. Cleavage is blocked by b

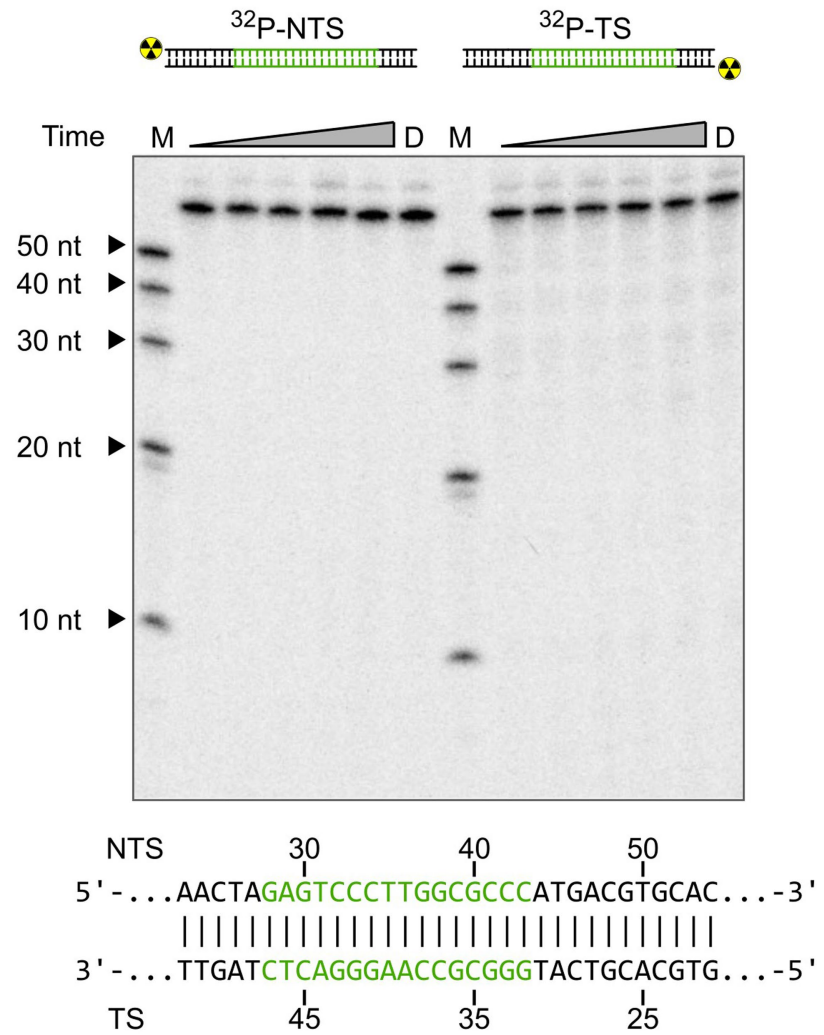

D191A mutation at the RuvC-like active site (lane D). NTS and TS represent non-target and target strand, respectively. M - DNA marker lane. For uncropped gel images, see Supplementary Fig. 2. 


\section{Article}

a

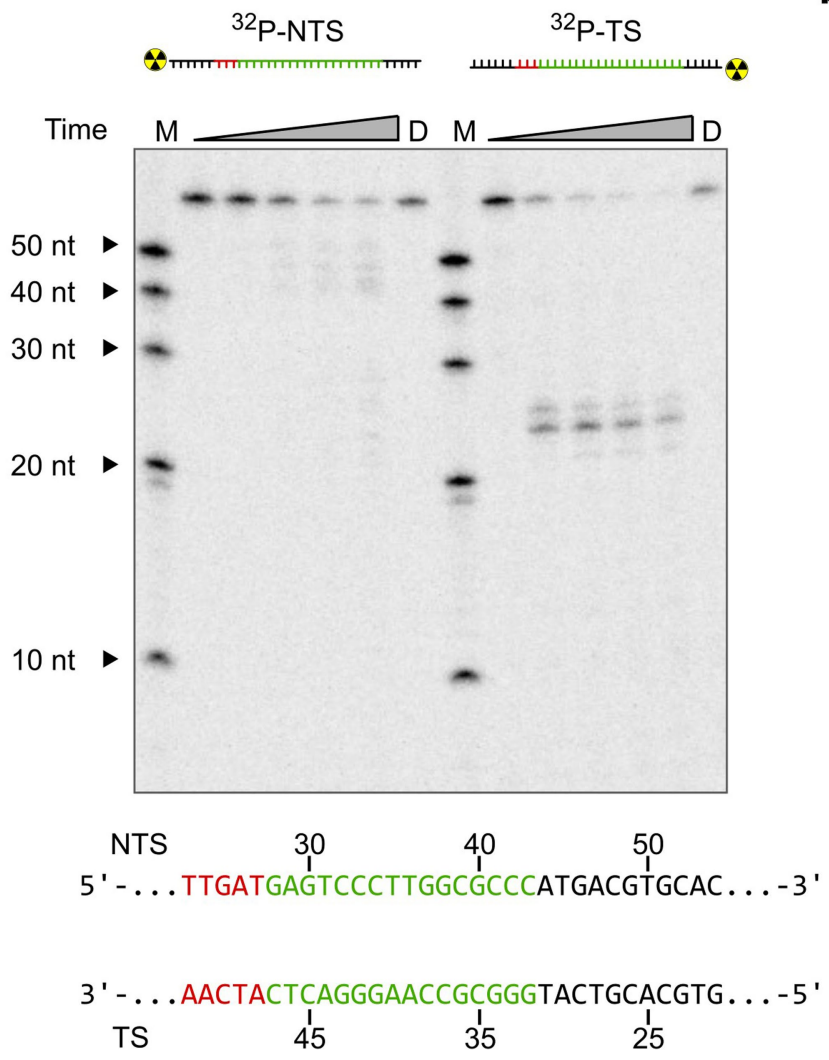

Extended Data Fig. 6 | Synthetic ssDNA cleavage by TnpB RNP complex. $\mathbf{a}, \mathbf{b}$, Cleavage of ssDNA substrates containing a target (represented in green colour) with TAM (red colour) (a) or without TAM sequence (b). TnpB RNP complex cleaves sSDNA in a TAM-independent manner. Cleavage is blocked by b

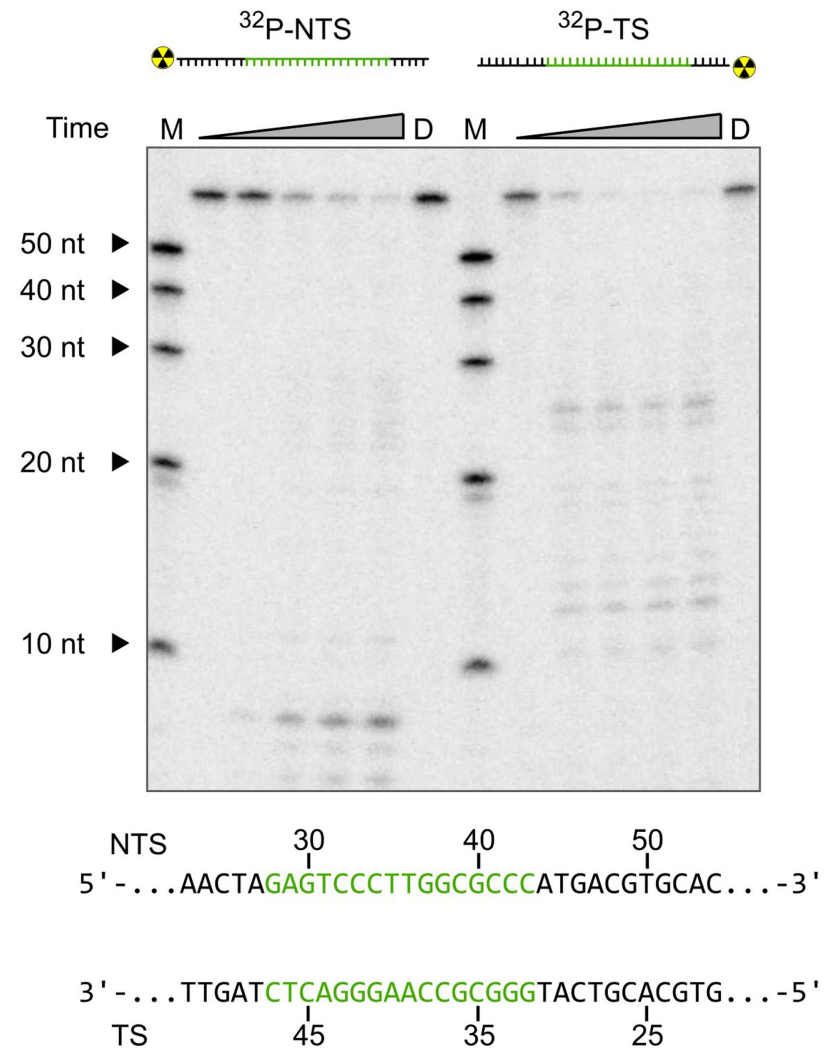

D191A mutation at the RuvC-like active site (lane D). NTS and TS represent non-target and target strand, respectively. M-DNA marker lane. For uncropped gel images, see Supplementary Fig. 2. 
a

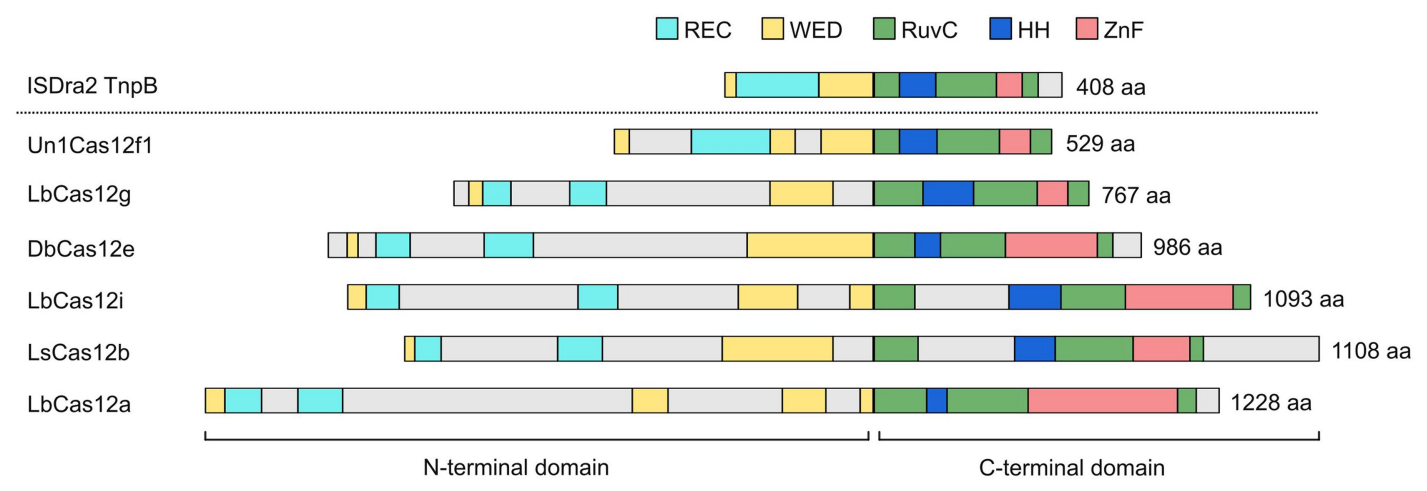

b

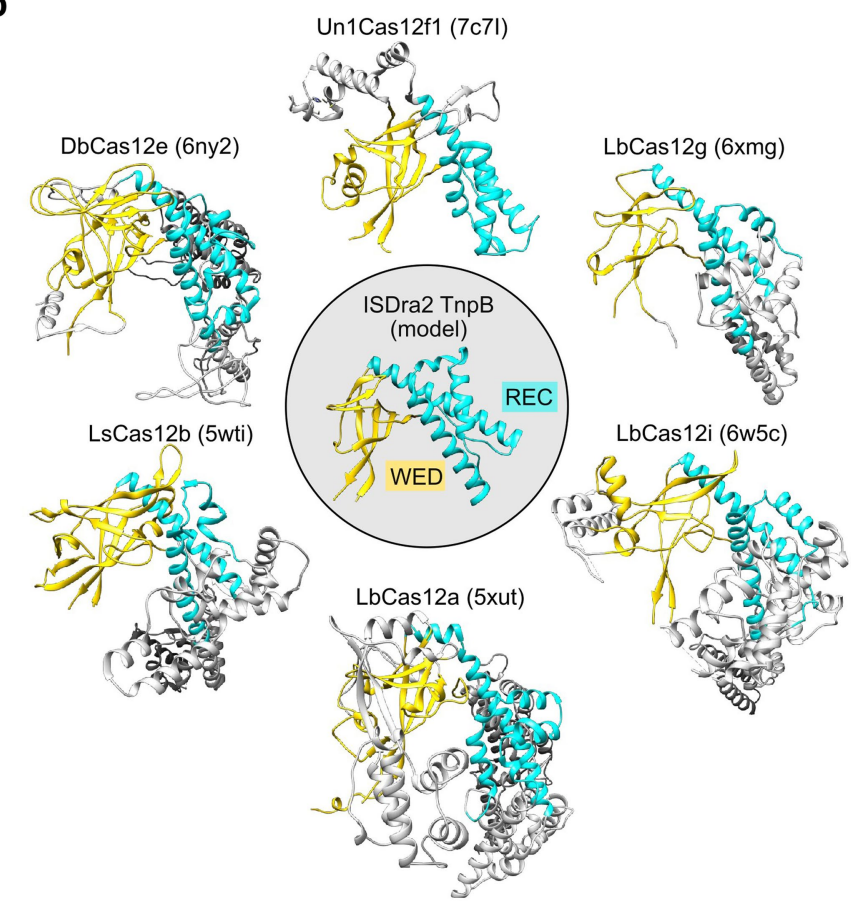

Extended Data Fig. 7 | Comparison of a TnpB model with experimentally determined representative structures of different Cas12 groups.

a, Schematic representation of common structural domains/motifs (coloured) and unique structural regions (grey) along the sequence; WED - wedge domain, corresponding to the $\beta$-barrel, REC - helical bundle, RuvC - RuvC domain with the inserted helical hairpin $(\mathrm{HH})$ and either the zinc-finger domain $(\mathrm{ZnF})$, or analogous domain inserted in the same relative position. Length of all
C

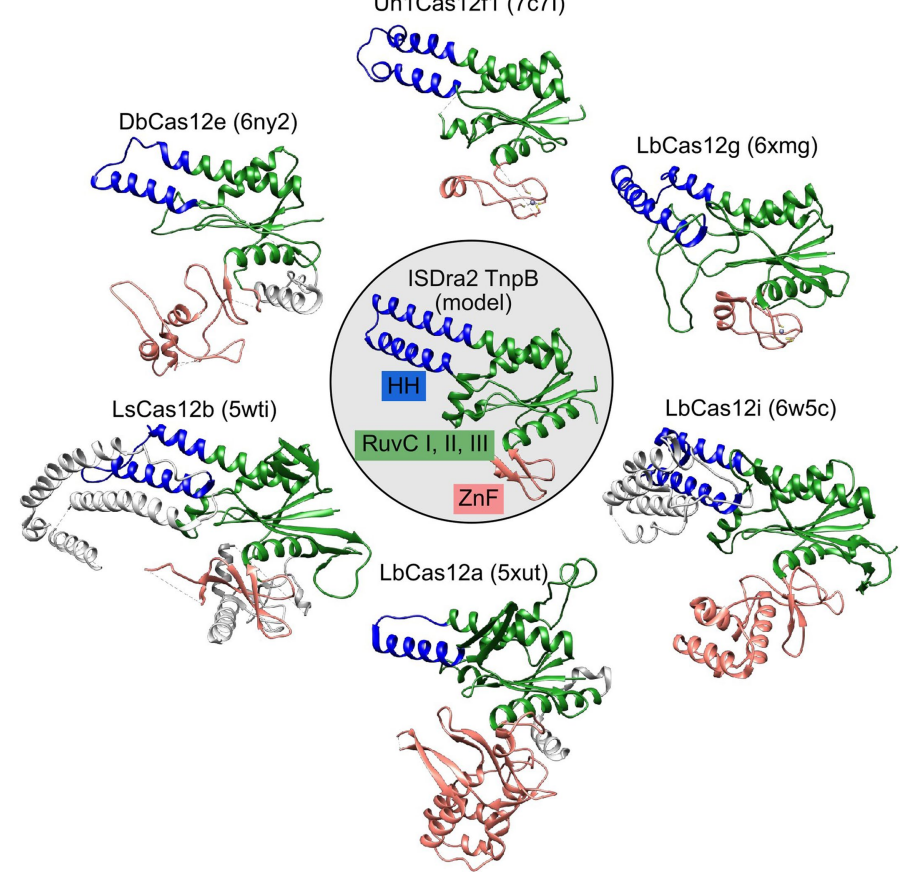

sequences are approximately to scale. TnpB represents a minimal domain organization also present in Cas12 groups. b, Comparison of $\mathrm{N}$-terminal regions between TnpB and other Cas12 proteins; the $\mathrm{N}$-terminal WED and REC domains are involved in PAM recognition in Cas $12 \mathrm{f}$ and are expected to participate in TAM recognition in TnpB.c, Comparison of corresponding RuvC regions. 


\section{Article}

Extended Data Table 1 | Comparison of biochemical features of RNA-guided nucleases adopted for genome editing

RNA-guided genome editor

System

Protein

gRNA

Effector complex

(protein:gRNA)

Nuclease

active site

dsDNA target
Cas9

CRISPR-Cas

1000-1500 aа

crRNA and tracrRNA

$1: 1$

$\mathrm{HNH}$ and RuvC

Target and 3' PAM
Cas12

CRISPR-Cas

500-1500 aa

crRNA or crRNA and tracrRNA

$1: 1$ or $2: 1$ (Cas12f)

RuvC

5' PAM and target
TnpB

IS200/IS605 and IS607

400 aa

reRNA

$1: 1$

RuvC

5' TAM and target 


\section{nature portfolio}

Corresponding author(s): Tautvydas Karvelis and Virginijus Siksnys

Last updated by author(s): Sep 20, 2021

\section{Reporting Summary}

Nature Portfolio wishes to improve the reproducibility of the work that we publish. This form provides structure for consistency and transparency in reporting. For further information on Nature Portfolio policies, see our Editorial Policies and the Editorial Policy Checklist.

\section{Statistics}

For all statistical analyses, confirm that the following items are present in the figure legend, table legend, main text, or Methods section.

n/a Confirmed

$\square$ The exact sample size $(n)$ for each experimental group/condition, given as a discrete number and unit of measurement

$\square$ A statement on whether measurements were taken from distinct samples or whether the same sample was measured repeatedly

Х The statistical test(s) used AND whether they are one- or two-sided

Only common tests should be described solely by name; describe more complex techniques in the Methods section.

$\bigotimes \square$ A description of all covariates tested

Х $\square$ A description of any assumptions or corrections, such as tests of normality and adjustment for multiple comparisons

$\triangle$ A full description of the statistical parameters including central tendency (e.g. means) or other basic estimates (e.g. regression coefficient)

AND variation (e.g. standard deviation) or associated estimates of uncertainty (e.g. confidence intervals)

$\triangle \square$ For null hypothesis testing, the test statistic (e.g. $F, t, r$ ) with confidence intervals, effect sizes, degrees of freedom and $P$ value noted

$\triangle$ Give $P$ values as exact values whenever suitable.

$\bigotimes \square$ For Bayesian analysis, information on the choice of priors and Markov chain Monte Carlo settings

Х $\square$ For hierarchical and complex designs, identification of the appropriate level for tests and full reporting of outcomes

\ $\square$ Estimates of effect sizes (e.g. Cohen's $d$, Pearson's $r$ ), indicating how they were calculated

Our web collection on statistics for biologists contains articles on many of the points above.

\section{Software and code}

Policy information about availability of computer code

Data collection Next-generation sequencing data was obtained using Illumina MiSeq and MiniSeq platforms

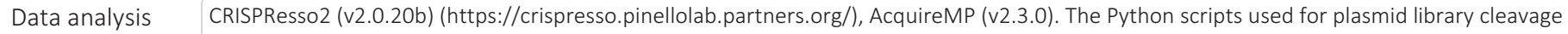
position identification and TAM characterization are provided at GitHub repository (https://github.com/tkarvelis/Nuclease_manuscript).

For manuscripts utilizing custom algorithms or software that are central to the research but not yet described in published literature, software must be made available to editors and reviewers. We strongly encourage code deposition in a community repository (e.g. GitHub). See the Nature Portfolio guidelines for submitting code \& software for further information.

\section{Data}

Policy information about availability of data

All manuscripts must include a data availability statement. This statement should provide the following information, where applicable:

- Accession codes, unique identifiers, or web links for publicly available datasets

- A description of any restrictions on data availability

- For clinical datasets or third party data, please ensure that the statement adheres to our policy

All data are available in the manuscript and the supplementary material. Additionally, sRNA and plasmid library cleavage sequencing data are available on the NCBI Sequence Read Archive under BioProject ID PRJNA723137. ISfinder database was accessed at https://isfinder.biotoul.fr. 


\section{Field-specific reporting}

Please select the one below that is the best fit for your research. If you are not sure, read the appropriate sections before making your selection.

\ Life sciences $\quad \square$ Behavioural \& social sciences $\quad \square$ Ecological, evolutionary \& environmental sciences

For a reference copy of the document with all sections, see nature.com/documents/nr-reporting-summary-flat.pdf

\section{Life sciences study design}

All studies must disclose on these points even when the disclosure is negative.

Sample size Sample size $(n=3)$ was based on the work and experience of other groups in the field who generate reproducible results in the similar design experiments with the cells (no statistical methods were used to determine the sample size).

Data exclusions No data was excluded from the analysis.

Replication Reproducibility was ensured by repeating most of the experiments independently at least 3 times.

Randomization Samples were not randomized as it is not applicable for the current design of the study.

Blinding Investigators were not blinded as it is not applicable for the current design of the study.

\section{Reporting for specific materials, systems and methods}

We require information from authors about some types of materials, experimental systems and methods used in many studies. Here, indicate whether each material, system or method listed is relevant to your study. If you are not sure if a list item applies to your research, read the appropriate section before selecting a response.

Materials \& experimental systems

$\mathrm{n} / \mathrm{a}$ Involved in the study

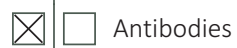

$\square$ Eukaryotic cell lines

Х $\square$ Palaeontology and archaeology

\ $\square$ Animals and other organisms

\ $\square$ Human research participants

$\square$ Clinical data

Х $\square$ Dual use research of concern

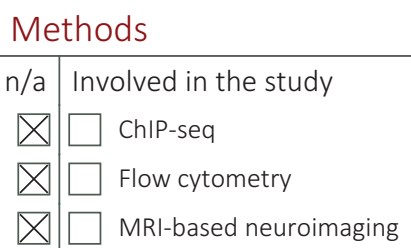

\section{Eukaryotic cell lines}

Policy information about cell lines

Cell line source(s)

HEK293T cell line was obtained from ATCC (CRL-3216 ${ }^{\mathrm{TM}}$ ).

Authentication

HEK293T cell line was not authenticated.

Mycoplasma contamination

Commonly misidentified lines (See ICLAC register)
HEK293T cell line was not tested for mycoplasma contamination.

HEK293T cell line is not listed in the ICLAC register of misidentified cell lines. 